University of Arkansas, Fayetteville

ScholarWorks@UARK

$5-2020$

\title{
Surface Modified Polypropylene Membranes for Treating Hydraulic Fracturing Produced Waters by Membrane Distillation
}

Tharaka Hawpe Gamage

University of Arkansas, Fayetteville

Follow this and additional works at: https://scholarworks.uark.edu/etd

Part of the Environmental Engineering Commons, Fresh Water Studies Commons, Membrane Science Commons, and the Water Resource Management Commons

\section{Citation}

Hawpe Gamage, T. (2020). Surface Modified Polypropylene Membranes for Treating Hydraulic Fracturing Produced Waters by Membrane Distillation. Graduate Theses and Dissertations Retrieved from https://scholarworks.uark.edu/etd/4054

This Thesis is brought to you for free and open access by ScholarWorks@UARK. It has been accepted for inclusion in Graduate Theses and Dissertations by an authorized administrator of ScholarWorks@UARK. For more information, please contact scholar@uark.edu. 
Surface Modified Polypropylene Membranes for Treating Hydraulic Fracturing Produced Waters by Membrane Distillation

A thesis submitted in partial fulfillment

of the requirements for the degree of

Master of Science in Microelectronics-Photonics

by

Tharaka Hawpe Gamage

Southeast Missouri State University

Bachelor of Science in Engineering Physics, 2015

May 2021

University of Arkansas

This thesis is approved for recommendation to the Graduate Council.

Ranil Wickramsinghe, Ph.D.

Dissertation Director

Xianghong Qian, Ph.D.

Ingrid Fritsch., Ph.D.

Committee Member

Committee Member

Rick Wise, Ph.D.

Ex-Officio Member 
The following signatories attest that all software used in this thesis was legally licensed for use by Tharaka Gamage for research purposes and publication.

Mr. Tharaka Hawpe Gamage, Student

Dr. Ranil Wickramasinghe, Thesis Director

This thesis was submitted to http://www.turnitin.com for plagiarism review by the TurnItIn company's software. The signatories have examined the report on this thesis that was returned by TurnItIn and attest that, in their opinion, the items highlighted by the software are incidental to common usage and are not plagiarized material.

Dr. Rick Wise, Program Director

Dr. Ranil Wickramasinghe, Thesis Director 


\begin{abstract}
Membrane distillation is an emerging technology for treating hydraulic fracturing flowback and produced waters. Suppression of membrane fouling by inorganic and polar and non-polar organic compounds is a challenge. Here polyhydroxyethyl methacrylate, polyacrylic acid, polvinylallyl imidazolium bromide and polyvinylhexyl imidazolium bromide chains have been grafted from the membrane surface. Fouling is initially due to adsorption of organic compounds followed by scale formation. When challenged with produced water, membranes modified with polvinylallyl imidazolium bromide chains provided the greatest resistance to fouling. For EC pretreated produced water and synthetic produced water that contained mainly inorganic species, the flux decline was much less.
\end{abstract}




\section{Acknowledgements}

First and foremost, I would like to express my sincere gratitude to my advisor Dr. Ranil Wickramasinghe for his continuous support, patience, encouragement, and immense knowledge. I greatly appreciate all his contributions of time, ideas, and funding to make my learning experience very productive. I also appreciate all the support, encouragement, and knowledge I received from Dr. Rick Wise, the Director of the Microelectronics-Photonics program. I'm very thankful to my committee members, Dr. Ingrid Fritsch and Dr. Xianghong Qian, along with all other faculty and staff in the Microelectronics-Photonics program for their advice and help along the way. I also would like to acknowledge all the support, encouragement, and knowledge I received from Dr. Arijith Senguptha.

The membrane characterization studies discussed in this thesis would not have been possible without the high-quality SEM and EDX analysis from the Arkansas Nano-Bio Materials Characterization Facility. I would like to thank Dr. Mourad Benamara for his support with the above-mentioned analysis. Moreover, I would like to thank Dr. Vu for his help with contactangle and FTIR measurements. Raw and treated produced waters have been characterized and these efforts could not have been possible without the help from Arkansas Water Resources Center, University of Arkansas staff.

I greatly acknowledge the funding sources that made this research work possible. This research work was funded by Arkansas Research Alliance the University of Arkansas as well as

Southwestern Energy through the National Science Foundation Industry/University Cooperative Research Center for Membrane Science, Engineering and Technology, the National Science Foundation (IIP 1361809) and the University of Arkansas.

I would also like to thank Ms. Renee Hearon, Ms. Amber Friday-Brown and Ms. Kim 
W. Russel their continuous support and providing all the necessities to make my course work and experimental work productive.

I am very grateful for my research group members and microEP cohort members for their continues support, knowledge and feedback. Lastly, I would like to thank my family for all their love and encouragement. I would also like to thank my wife for her support during my study.

Thank you.

Tharaka Hawpe Gamage 


\section{Dedication}

I would like to dedicate this to everyone in the University of Arkansas community. 


\section{Table of Contents}

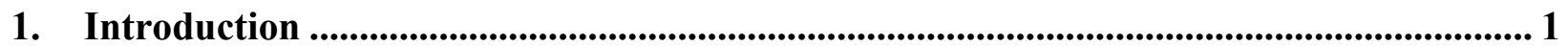

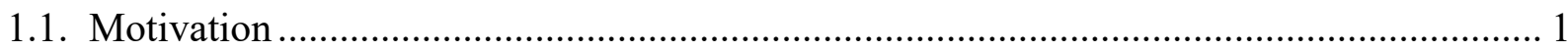

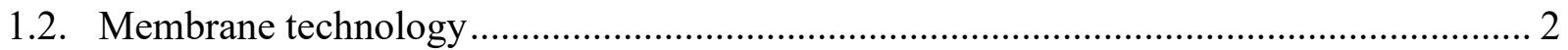

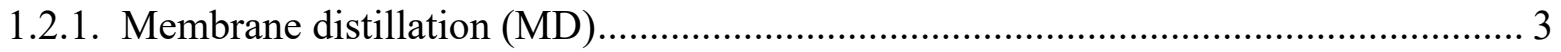

1.2.2. Membrane Fouling and scaling .......................................................................... 5

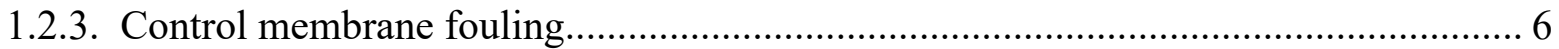

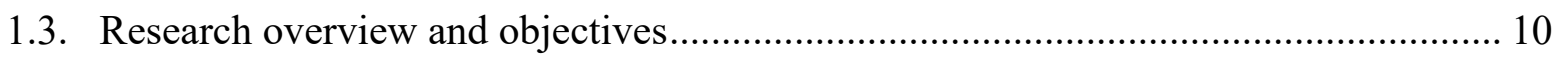

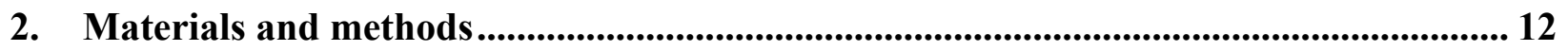

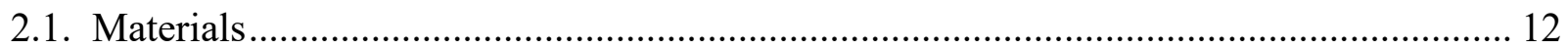

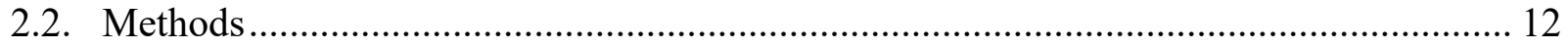

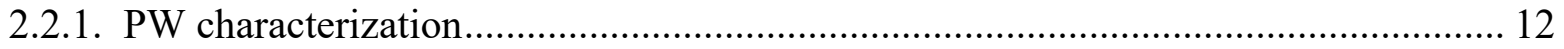

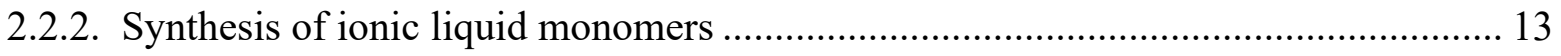

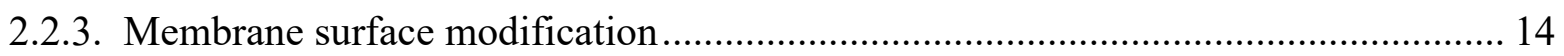

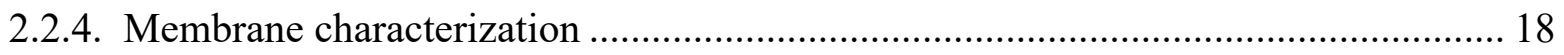

2.2.5. Direct Contact Membrane distillation (DCMD)............................................... 19

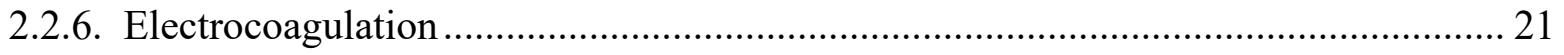

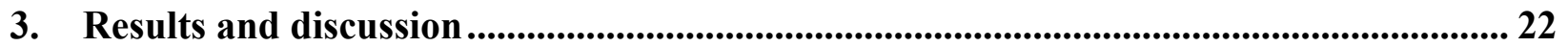

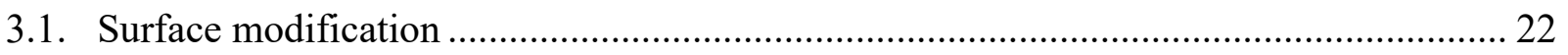

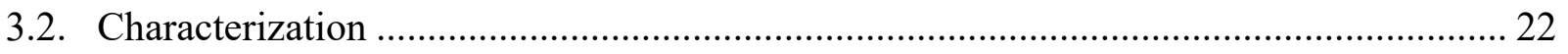

3.2.1. Fourier-transform infrared spectroscopy (FTIR) ............................................. 22

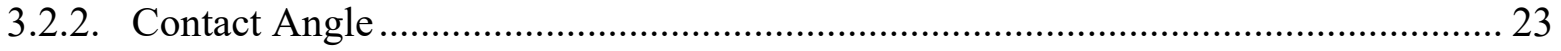

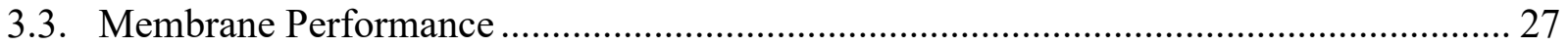

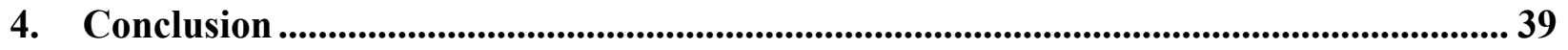

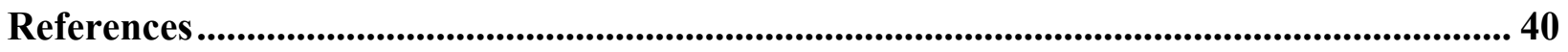

Appendix A: Description of Research for Popular Publication ........................................... 46

Appendix B: Executive Summary of Newly Created Intellectual Property ........................... 48

Appendix C: Potential Patent and Commercialization Aspects of listed Intellectual

Property Items...................................................................................................................49

C.1 Patentability of Intellectual Property (Could Each Item be Patented)............................. 49

C.2 Commercialization Prospects (Should Each Item Be Patented)..................................... 49

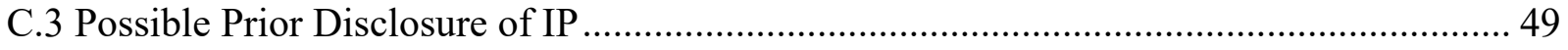


Appendix D: Broader Impact of Research .............................................................................. 51

D.1 Applicability of Research Methods to Other Problems.............................................. 51

D.2 Impact of Research Results on U.S. and Global Society ........................................... 51

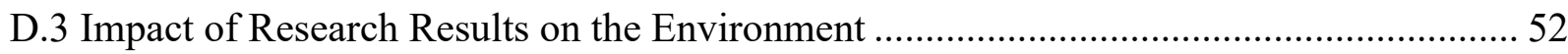

Appendix E: Microsoft Project for MS MicroEP Degree Plan .......................................... 53

Appendix F: Identification of All Software Used in Research and Thesis Generation ........ 55

Appendix G: Publications Published, Submitted, and Planned .............................56

Appendix H: Copyright Information..................................................57 


\section{List of Figures}

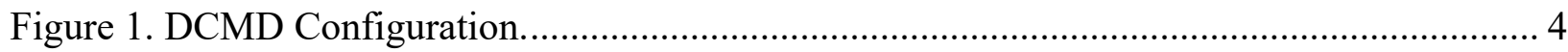

Figure 2. Schematic diagram of the DCMD set up............................................................... 19

Figure 3. Modification of PP membrane by HEMA, AA, allyl and hexyl-based monomers....... 23

Figure 4. FTIR spectra for the modified membranes................................................................ 24

Figure 5. FTIR spectra for the modified membranes using water.............................................. 24

Figure 6. Enhancement of carbonyl peak intensity for HEMA modified membranes at different UV time.

Figure 7. Enhancement of carbonyl peak intensity for AA modified membranes at different

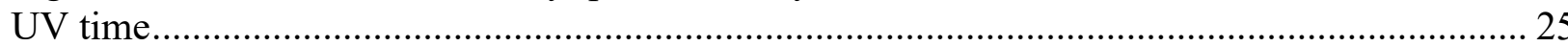

Figure 8. Enhancement of imidazolium peak intensity for allyl modified membranes at

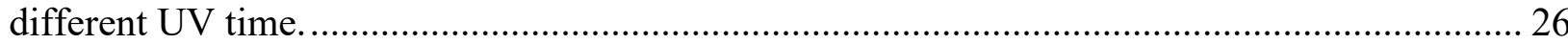

Figure 9. Enhancement of imidazolium peak intensity for bromo modified membranes at different UV time. 26

Figure 10. Variation of flux with distillate volume for modified membranes obtained by (a) 5 min UV grafting; (b) 10 min UV grafting. The feed stream was PW. ...................................... 28

Figure 11. Flux versus distillate volume for consecutive MD cycles: base PP membrane. ......... 29

Figure 12. Flux versus distillate volume for consecutive MD cycles: HEMA modified

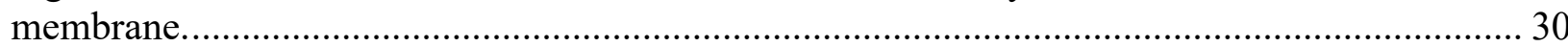

Figure 13. Flux versus distillate volume for consecutive MD cycles: AA modified membrane.

Figure 14. Flux versus distillate volume for consecutive MD cycles: allyl modified membrane.

Figure 15. Flux versus distillate volume for consecutive MD cycles: hexyl modified. membrane

Figure 16. The flux versus distillate volume transfer for 2nd MD cycle using modified PPmembranes (5 min benzophenone, 10 min UV)....

Figure 17. FTIR spectra of fouled membranes after processing PW by DCMD......................... 32 
Figure 18. Variation of flux with distillate volume for allyl and base PP membranes. Results are given for PW, EC pretreated PW, and synthetic PW

Figure 19. SEM characterization of fouled membranes : base membrane after the first DCMD run: (a) base membrane challenged with PW; (b) base membrane challenged with EC pretreated PW; and, (c) base membrane challenged with synthetic PW, 5 mins polymerized. allyl modified membrane after the first DCMD run : d) allyl modified membrane challenged with PW; (e) allyl modified membrane challenged with EC pretreated PW; and, (f) allyl modified membrane challenged with synthetic PW 


\section{List of Tables}

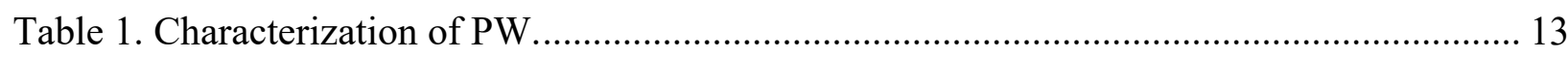

Table 2. Summary of modification procedure. ................................................................... 17

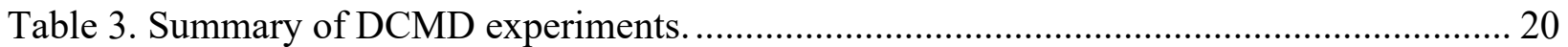

Table 4. Water contact angles for the modified membranes obtained from different UV exposure (average of five experiments conducted with ph $6 \mathrm{dI}$ water) .................................... 27

Table 5. The water contact angles for the modified membranes using water........................... 27

Table 6. EDX analysis of fouled membranes. .................................................................. 37 
List of Published Papers Used in this Dissertation

Large parts of Chapters 1, 2, 3, and 4 were published as:

Tharaka Gamage, Arijit Sengupta \& S. Ranil Wickramasinghe "Surface modified polypropylene membranes for treating hydraulic fracturing produced waters by membrane distillation", Separation Science and Technology, vol. 54:17, p. 2921-2932, 2019 DOI:

10.1080/01496395.2019.1611854 


\section{Introduction}

\subsection{Motivation}

Freshwater is essential to everyday societal activities. Discharging wastewater containing organic and inorganic contaminants can be harmful to ecosystems and fresh water systems [1-3]. As oil and natural gas production is increasing to meet the demands of modern society, generation of large volumes of waste streams are also increasing. These oil and gas waste streams or produced water (PW) contain an extensive amount of organic and inorganic components [1]. Discharging this PW to the environment can be very harmful to surface water as well as underground water and soil. Since this PW is generated in large volumes, there is a growing need for efforts to find efficient and environmentally friendly methods to treat and remove pollutants in the PW. This can also provide a supplemental solution for limited fresh water resource. Following contaminants can be found in PW [2,4]:

- Salt, which is referred as salinity or total dissolved solids (TDS)

- Oil and grease

- Chemical additives used in drilling

- Naturally occurring radioactive material.

There is a rapid growth of natural gas production using horizontal drilling and high volume hydraulic fracturing in the United States (U.S.) [5]. According to the U.S. Energy Information Administration, 15.8 trillion cubic feet (Tcf) of natural gas was produced the U.S. in $2016[6,7]$.

Hydraulic fracturing PW is considered as the largest waste produced in the oil and gas industry due to large quantities of PW generated form hydraulic fracturing process. Management and disposal of this PW have become some of the biggest challenges in the oil and gas 
development industry [5,8]. Deep-well injection is the primary method of disposal and management of these high salinity PWs. This process could cost up to 10 to 15 USD per barrel of PW $[8,9]$. In addition to the high operation costs, U.S. geological survey (USGS) has recently discovered that the deep-well injection wastewater disposal is responsible for increasing earthquakes in the U.S. [10]. Therefore, there is an urgent need for novel processes to eliminate or minimize the deep-well injection.

\subsection{Membrane technology}

Membrane technology plays a vital role in wastewater treatment applications. A membrane can be utilized as a barrier that limits transport of undesired species and enables transport of targeted desired species by convection or diffusion of individual compounds. Mass transfer across a membrane can be driven by concentration, pressure or temperature gradient [11]. Due to simplicity, easiness-to-operate, low-maintenance process with minimal use of added chemicals, membrane-based separation technologies have been increasingly used for a wide range of applications during the past two decades.

Membrane techniques such as microfiltration (MF), ultrafiltration (UF), reverse osmosis (RO) and membrane distillation (MD) are very widely used in wastewater treatment applications due to many of their advantages $[8,12]$. They can reduce the complexity of the purification process by reducing operation units and recycle process water. Also, membrane technology enables a convenient, continuous and selective separation, purification process without additional chemicals and low space requirement.

MD has proven to be a promising desalination technology $[8,13]$. MD can be operated in relatively lower temperature than conventional vapor pressure driven processes. Since the feed solution does not need to be heated to the boiling point, waste heat can be utilized as the energy 
source. Lower operation temperatures allow cheaper materials such as plastic to be used which can also alleviate corrosion issues $[14,15]$. Also, the hydrostatic pressure in MD is relatively lower than the pressure driven membrane processes such as reverse osmosis which can lower operation costs. Literature also states that $\mathrm{MD}$ has a higher rejection rates allowing almost complete separation $[8,13]$. MD is an emerging membrane-based separation process for treating high salinity wastewaters [16].

\subsubsection{Membrane distillation (MD)}

MD is a thermally driven separation process which utilizes a hydrophobic membrane to transport water vapor from the feed side to the permeate side. The vapor pressure difference caused by the temperature difference between the feed side and the permeate side drives the MD process. This allows MD to operate at lower temperatures than the conventional thermal distillation. As long as the transmembrane pressure is not higher than the liquid entry pressure of the membrane, the hydrophobicity of the membrane prevents water solution from penetrating through the membrane [8].

The mass transport process from feed side to permeate can be divided into three different steps: (1) formation of a water/vapor interface at the feed solution (at the entrance of the pores); (2) transport of the vapor through the hydrophobic membrane; and, (3) condensation of the vapors at permeate solution and membrane interface $[17,18]$. Usually this transported mass is referred to as flux.

There are several configurations used in MD. The main difference between these configurations is in the permeate side condensing and collecting vapor. In this research, direct contact membrane distillation (DCMD) configuration was used to drive the flux using the vapor pressure gradient between the two surfaces of the hydrophobic membrane $[19,20]$. In DCMD, 
the liquid in the feed side is at a higher temperature than the DI water used as condensing fluid in distillate side. Both feed and distillate liquids are in direct contact with the hydrophobic membrane. This is a very commonly used MD configuration due to the convenience of setting up in laboratory environment $[8,13,19,20]$. The hydrophobic microporous membrane acts as a physical barrier between the two sides (feed and the distillate) of the membrane. Water and other volatile components in the hot feed side vaporize and pass through the hydrophobic membrane pores and condense on the cold distillate side. Figure 1 illustrates the concept of DCMD.

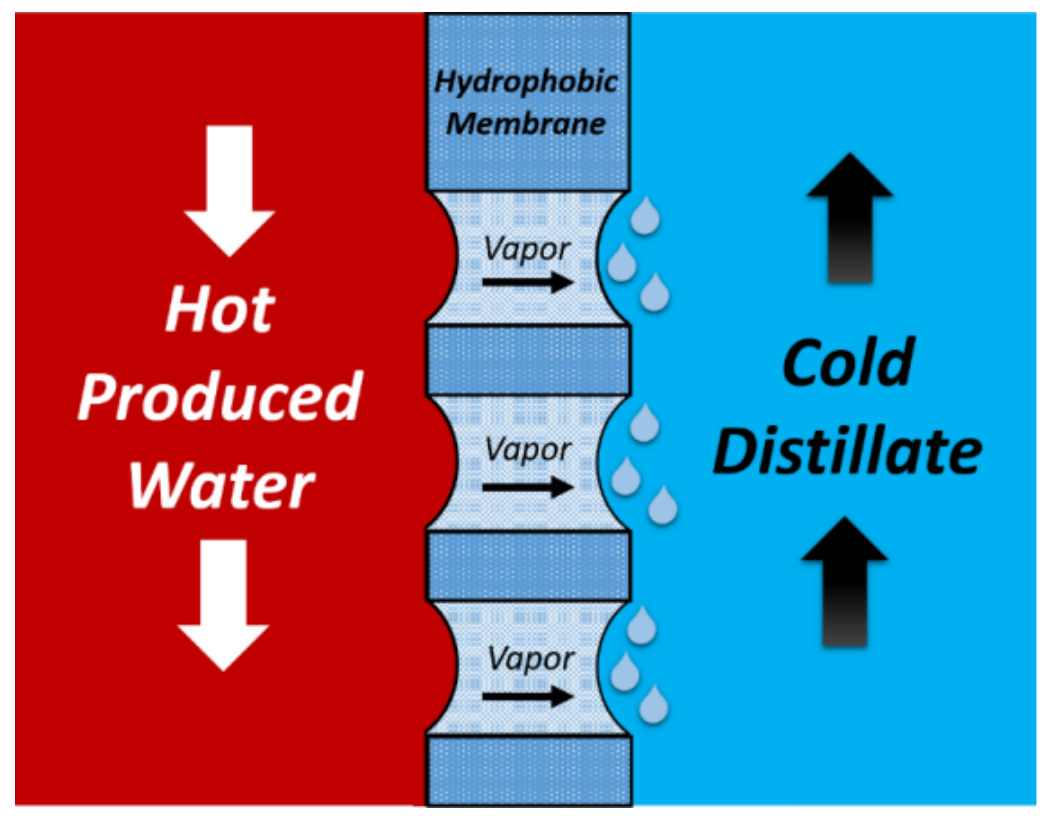

Figure 1. DCMD Configuration.

Hydrophobic microporous membrane used in DCMD enables complete rejection of nonvolatile compounds such as cations, anions, organic species, inorganic colloidal, etc. Unlike other membrane separation processes, the efficiency of the driving force for vapor transport is not significantly affected by feed salinity. In MD, feed water temperatures are in the range of 35 
$-70{ }^{\circ} \mathrm{C}$, which are lower than temperature used in conventional distillation processes. Therefore, MD has the potential of using waste heat streams or alternative energy sources to drive the process. In addition, the possibility of using plastic equipment due to lower temperatures, also reduces corrosion problems and material costs $[14,15]$.

However, costs such as power, labor, materials, membrane cleaning, and replacing are major concerns in operating membrane systems. There are some issues that drive these operation costs higher. Two of the major factors that increase the cost of operation are membrane fouling and scaling [16,21].

\subsubsection{Membrane Fouling and scaling}

The process which decreases the membrane performance (flux) due to suspended or dissolved solids adsorption or deposition on the membrane surface or inside the membrane pores is called membrane fouling. This process can cause higher energy use, higher cleaning frequency, and shorter life time of a membrane which increases the above mentioned operational costs $[8,21]$.

Due to the simultaneous presence of higher organic content as well as total dissolved solid in terms of ions; the MD for the treatment of PW can suffer significant membrane fouling, especially due to the hydrophobic interaction of the organic matter on the membrane surface (though MD can take care of high TDS water streams). Inorganic scalants and organic and biological foulants can get deposited, adsorbed, and accumulate on the membrane surface or/and inside membrane pores. This could negatively impact water productivity and membrane lifespan. Fouling and scaling can cause temperature polarization which has a significant impact on transmembrane mass transport [16]. Apart from performance decline of the membrane, fouling 
and scaling can also cause pore wetting. Once the pores are wet, feed water can pass through the membrane to the distillate side failing the process. Surfactants and/or low surface tension foulants present in the feed water are usually responsible for membrane pore wetting [22-28].

In this experiment DCMD has been used to treat hydraulic fracturing PW. MD holds the promise of being a viable process for treating industrial wastewaters from non-conventional oil and gas production facilities, there are numerous challenges that must be overcome [16]. Here we focus on one of these key challenges, development of more fouling resistant membranes. Hydraulic fracturing flow back and PW are complex as they contain not only high TDS but also low molecular weight polar and non-polar organic compounds. Membrane fouling can lead to flux decline due to the presence of additional mass transfer resistance as a result of the fouling layer. In addition, it can lead to pore wetting resulting in liquid water passing through the membrane pores. This will result in the passage of non-volatile components passing into the distillate compromising the distillate quality [22-25].

\subsubsection{Control membrane fouling}

Lately, a primary goal of research has been optimizing and tailoring membrane surface properties to address wettability to minimize fouling tendency and pore wetting of membranes $[23,24,29]$. However, irrespective of the membrane surface modification, pretreatment of the feed stream is essential. Development of more fouling resistant membranes will lead to increased membrane lifetimes as well as lower pretreatment requirements.

\section{Pretreatment}

Various pretreatment methods have been used prior to performing membrane separation [21]. Chemical coagulation is a frequently used method to remove colloidal and organic 
compounds from waste water [30]. In this work, electrocoagulation (EC) is given the focus for removal of suspended and dissolved organic species that could lead to membrane fouling in MD. $\mathrm{EC}$ is an electrochemical pretreatment process used in treating waste water using sacrificial electrodes to release coagulant into waste water solution [31]. In this research, aluminum electrodes were used.

EC and alum based chemical coagulation share similar fundamental chemical reactions. In chemical coagulation, aluminum sulfate salts such as alum, $\mathrm{Al}_{2}\left(\mathrm{SO}_{4}\right)_{3} .18 \mathrm{H}_{2} \mathrm{O}$ are frequently added in the process $[9,32]$. Dissolved and suspended species and $\mathrm{pH}$ of the solution have a high effect on the chemical coagulation process. Eq. 1 and Eq. 2 show overall reaction after alum is added and dissolution of the salt.

$$
\begin{gathered}
\mathrm{Al}_{2}\left(\mathrm{SO}_{4}\right)_{3} \cdot 18 \mathrm{H}_{2} \mathrm{O} \rightarrow 2 \mathrm{Al}^{3+}+3\left(\mathrm{SO}_{4}\right)^{2-}+18 \mathrm{H}_{2} \mathrm{O} \\
2 \mathrm{Al}^{3+}+3\left(\mathrm{SO}_{4}\right)^{2-}+18 \mathrm{H}_{2} \mathrm{O} \rightarrow 2 \mathrm{Al}(\mathrm{OH})_{3}+6 \mathrm{H}^{+}+3\left(\mathrm{SO}_{4}\right)^{2-}+18 \mathrm{H}_{2} \mathrm{O}
\end{gathered}
$$

As the solution ages, the concentration of aluminum in the solution increases and aluminum hydroxide get deposited in solid form as shown by Eq. 3 [9,33]. Literature indicates that formation of numerous polymeric species helps to drive the adsorption of colloidal to the aluminum species and precipitation mechanisms [33].

$2 \mathrm{Al}^{3+}+\mathrm{n} \mathrm{OH}^{-} \rightarrow \mathrm{Al}(\mathrm{OH})_{\mathrm{n}}{ }^{3-\mathrm{n}} \rightarrow \mathrm{Al}_{2}(\mathrm{OH})_{2}{ }^{4+} \rightarrow \mathrm{Al}_{\mathrm{n}}($ Complex $) \rightarrow \mathrm{Al}(\mathrm{OH})_{3}(\mathrm{~s})$

However, EC has number of advantages over the chemical coagulation methods [34]. Since the coagulant is produced in situ using aluminum electrode at the anode, it helps to prevent addition of liquid coagulant. Also, the $\mathrm{pH}$ does not change with the breakdown of the coagulation agent due to the reaction with water. The amount of coagulants used in EC and 
produced sludge is less compared to other chemical coagulation practices $[9,35]$.

In the EC reactor, the following electrode reactions occur after the voltage is applied [9]:

Anode: $\mathrm{Al} \rightarrow \mathrm{Al}^{3+}+3 \mathrm{e}^{-}$

(Equation 4)

Cathode: $3 \mathrm{H}_{2} \mathrm{O}+3 \mathrm{e}^{-} \rightarrow 3 / 2 \mathrm{H}_{2}+3 \mathrm{OH}^{-}$

(Equation 5)

$\mathrm{Al}^{3+}$ and $\mathrm{OH}^{-}$ions produced by the anode and cathode react and form monomeric and polymeric aluminum species such as $\mathrm{Al}(\mathrm{OH})_{4-}, \mathrm{Al}(\mathrm{OH})^{2+}$, and $\mathrm{Al}(\mathrm{OH})_{153+}$ which eventually form amorphous $\mathrm{Al}(\mathrm{OH})_{3}(\mathrm{~s})$ with large surface area [33]. $\mathrm{The} \mathrm{Al}(\mathrm{OH})_{3}(\mathrm{~s})$ is in a form of a gelatinous suspension in the aqueous phase. $\mathrm{Al}(\mathrm{OH})_{3}(\mathrm{~s})$ can absorb and trap organic compounds and suspended solids. Electrostatic attraction between aluminum species and these compounds or complexation of these species will drive these mechanisms [9]. After trapping and adsorbing organic compounds and suspended colloidal, $\mathrm{Al}(\mathrm{OH})_{3}$ flocs will undergo polymerization and deposit according to the following reaction, allowing the removal of organic compounds and suspended solids from PW [9]:

$$
\mathrm{n} \mathrm{Al}(\mathrm{OH})_{3} \rightarrow \mathrm{Al}_{\mathrm{n}}(\mathrm{OH})_{3 \mathrm{n}}
$$

Some organic compounds and Al species with suspended solutes will agglomerate and develop low-density complexes. These low-density complexes are carried to the top of the separatory funnel (liquid-air interface) by up floating hydrogen bubbles produced at the cathode. These low-density complexes accumulate and densify leading to sedimentation as they sink to the bottom of the separatory funnel. Charged aluminum species such as $\mathrm{Al}(\mathrm{OH})^{2+}$ attract charged organic compounds and suspended solids to produce X-Al complexes by charge neutralization. These $\mathrm{Al}$ complexes are then get accumulated followed by floatation to the liquid-air interface by hydrogen gas or sedimentation at the bottom [36,37]. These mechanisms create three zones 
inside the separatory funnel: low-density flocs remain at the liquid-air interface, clear water remains at the middle region, and aggregated flocs get collected at the bottom. The clear water from the middle zone can be separated.

\section{Membrane surface modification}

Fouling may be suppressed by optimizing the membrane surface properties such that adsorption of foulants becomes thermodynamically unfavorable. However, the situation is complicated by the fact that dissolved ions, polar and non-polar organic species, are present in the hydraulic fracturing PW. Development of economically viable surface modification strategies for membranes used in MD will be challenging.

Therefore, research is focused on enhancing MD performances with super hydrophobic and omniphobic membranes [29]. However, hydrophobic-hydrophobic interactions can lead amphiphilic surfactants which have both hydrophobic and hydrophilic characteristics to get attached to a superhydrophobic surface. The hydrophobic end gets attached to the membrane surface leaving the hydrophilic end exposed to the solution, making the membrane surface hydrophilic. These surfactants also have the ability to reduce the surface tension of solutions leading the superhydrophobic membranes to wet $[16,24]$.

Omniphobic membranes, on the other hand, show resistance to wetting due to low surface tension solutions containing surfactant [16]. However, hydrophobic- hydrophobic interactions can lead non-polar organic contaminants such as oil to get attached to the omniphobic membrane surface. These non-polar organic contaminants can accumulate on the membrane surface blocking pores and reducing membrane performance $[16,38]$.

Research has shown hydrophilic surface modifications can provide resistivity toward wetting and fouling of MD membranes [16]. These hydrophilic surface modifications are done 
by adding a thin hydrophilic layer on the hydrophobic membrane surface to limit non-polar organic contaminant accumulation on the membrane surface which can suppress fouling by nonpolar organic species while the inner hydrophobic pore surface prevents the passage of liquid water through the membrane [16]. This helps to maintain a good membrane permeability, minimize the impact of temperature polarization, and lower the wetting tendency of hydrophobic membranes.

However, too much hydrophilic layer may result the passage of water across the membrane instead of vapor, deteriorating the distillation process. Therefore, careful tuning of surface hydrophilicity is required to process such complicated waste stream. Moreover, formation of biofilm on the membrane surface during processing waste stream is another major challenge. Therefore, hydrophobic membrane with thin tunable hydrophilicity with antimicrobial characteristic should be the ideal option for processing PW by MD.

Poly(ionic liquids) are polymers of ionic liquids having favorable properties of polymers blended with unconventional and unique properties of ionic liquids [39-43]. Its high degree of tunability by understanding structure-activity relationship provides an advantage in tuning the hydrophilicity of the surface modification. Moreover, the ionic liquid moieties were reported to have antimicrobial activity [44-46]. In view of these, hydrophilic modification on hydrophobic membrane using poly ionic liquid (PIL) would be successful in treatment of produced waste by MD and reduce the amount of pretreatment needed.

\subsection{Research overview and objectives}

Since, polypropylene (PP) is one of the prominent hydrophobic membranes used in MD, four different hydrophilic surface modifications of the base PP membrane were compared. Some studies indicate that a sufficiently thin hydrophilic layer grafted from the external surface of a PP 
membrane can suppress fouling by non-polar organic species while the inner hydrophobic pore surface prevents the passage of liquid water through the membrane $[16,38,47]$. However, the risk of scale formation by deposition of ionic species will increase. Performance of PIL modified PP membranes were evaluated with membranes modified by conventional monomers. The performance of the PIL grafted membrane was also compared with the EC as pretreatment technique.

Following are the objectives of this research work.

Objective (1): Modify commercially available polypropylene membranes in order to impart hydrophilicity using charged and non-charged polymers.

Objective (2): Determine performance of modified membranes when challenged with hydraulic fracturing PW.

Objective (3): Compare performance of modified membranes with base membranes using EC pretreated and non-pretreated hydraulic fracturing PW. 


\section{Materials and methods}

\subsection{Materials}

All chemicals are American Chemical Society (ACS) grade unless otherwise noted. Methanol was obtained from Sigma Aldrich, St. Louis, MO. Benzophenone and acrylic acid (AA) (SAJ Grade) were purchased from Acros Organics, Morris, NJ. 2-hydroxyethyl methacrylate (HEMA) was purchased from Alfa-Aesar, Ward Hill, MA. Deionized water from Thermo Fisher $18 \mathrm{M} \Omega$ Barnstead Smart2Pure system, Schwerte, Germany was used throughout the investigation. Vinyl imidazole, 1-bromohexane and allyl bromide were procured from Sigma Aldrich, St. Louis, MO (SAJ Grade). Polypropylene (PP) membrane was procured from 3M, Maplewood, MN.

\subsection{Methods}

\subsubsection{PW characterization}

PW samples obtained from the Fayetteville shale were provided by Southwestern Energy (Houston, TX) and these samples were pretreated to remove larger particles present. PW samples were characterized at the Arkansas Water Resources Center, University of Arkansas. Spectro Genesis ICP OES (Kleve, Germany) and Dionex DX-120 ion chromatograph (Sunnyvale, CA), were used to measure cations and anions present in these samples. EPA standard methods 160.1 and 160.2 were used to measure total dissolved solids (TDS) and total suspended solids (TSS), respectively [48,49]. A Skalar Formacs TOC analyzer (Breda, Netherlands) was used to measure total organic carbon (TOC). A Turb 550 (WTW, Weilheim, Germany) turbidity-meter was used to measure turbidity. The difference between the sum of cations and anions was used to determine the accuracy of the chemical analysis which is referred to as electroneutrality. The characterization of the PW is summarized in Table 1. 
Table 1. Characterization of PW.

\begin{tabular}{|lll|}
\hline Parameter & Raw PW, & Concentration, M \\
\hline TDS & $157,000 \mathrm{mgL}^{-1}$ & - \\
TSS & $1,277 \mathrm{mg} \mathrm{L}^{-1}$ & - \\
TOC & $11.9 \mathrm{mg} \mathrm{L}^{-1}$ & - \\
Turbidity & $273 \mathrm{NTU}$ 's & - \\
Calcium & $18,042 \mathrm{mg} \mathrm{L}^{-1}$ & 0.451 \\
Chloride & $102,200 \mathrm{mg} \mathrm{L}^{-1}$ & 2.878 \\
Magnesium & $1,248 \mathrm{mg} \mathrm{L}^{-1}$ & 0.052 \\
Sodium & $38,780 \mathrm{mg} \mathrm{L}^{-1}$ & 1.686 \\
Sulfate & $75.5 \mathrm{mg} \mathrm{L}^{-1}$ & 0.00078 \\
Electroneutrality & $<5 \%$ & - \\
\hline
\end{tabular}

Experiments were also conducted with a synthetic PW prepared using the main inorganic constituents of the PW: chloride, sodium, and calcium. $1.686 \mathrm{~mol}$ of $\mathrm{NaCl}$ and $0.451 \mathrm{~mol}$ of $\mathrm{CaCl}_{2}$ were added to DI water. In this way, the sodium and chloride ion concentrations matched that in the PW. Membrane distillation (MD) was also conducted using this synthetic PW to determine performance in the absence of dissolved organic compounds.

\subsubsection{Synthesis of ionic liquid monomers}

The synthesis of ionic liquid monomers was carried out by heating an equimolar amount of vinylimidazole with alkyl halide (allyl bromide and 1-bromohexane) at $300 \mathrm{~K}$ for $3 \mathrm{~h}$ as reported earlier [50]. This quaternization reaction generated an ionic liquid of straw yellow color and its formation was evidenced by clear phase separation. Ethyl acetate was used to wash the 
ionic liquid to remove unreacted reactant. 1-vinyl-3-allylimidazolium bromide and 1-vinyl-3hexylimidazolium bromide are the ionic liquid monomers used without further purification and, hence forth, termed as 'allyl' and 'hexyl', respectively.

\subsubsection{Membrane surface modification}

PP membranes have been grafted with polyhydroxyethyl methacrylate (poly HEMA), polyacrylic acid, polyvinylallyl imidazolium bromide and polyvinylhexyl imidazolium bromide chains from the membrane surface. PolyHEMA has been used frequently to hydrophilize the membrane surface [51,52]. Above the pKa for deprotonation of the first carboxylic group on the polyacrylic acid chains, the majority of the chains will be negatively charged.

However, though each polyacrylic acid chain contains multiple carboxylic groups, after deprotonation of the first group, deprotonation of subsequent carboxylic acid groups on the same chain is limited [53]. On the other hand, the two polyionic liquid chains contain multiple fixed positive charges. However, polyvinylhexyl imidazolium bromide will be more hydrophobic than polyvinylallyl imidazolium bromide due to the presence of the hexyl group. The inductive effect of the hexyl group decreases the positive charge on the imidazolium ring of the ionic liquid, while the $\mathrm{sp}^{2}$ hybridized allyl group has an electron withdrawing ability resulting in enhancement in positive charge on imidazolium ring. Hence, the substituent on imidazolium ring can tune the positive charge density on the imidazolium cation leading to tuning the hydrophilicity of the resulting polymer. As a control experiment, PP membranes were also modified using water instead of monomers to understand how water would react with photo initiated polymerization process and induce hydrophilicity on the PP membrane.

Surface modification is conducted using photo-initiated polymerization which is a very convenient process due to its ability to conduct initiation and polymerization simultaneously 
under the UV irradiation in the presence of a photo initiator. Benzophenone is used as the photo initiator, where the ground state benzophenone molecules absorb photons in the UV region. These excited benzophenone molecules will then abstract a hydrogen atom from the membrane surface to create surface radicals on the membrane [54].

$$
\begin{aligned}
& \text { photoexcitation: }\left(\mathrm{C}_{6} \mathrm{H}_{5}\right)_{2} \mathrm{C}=\mathrm{O}+\mathrm{UV} \rightarrow \quad\left(\mathrm{C}_{6} \mathrm{H}_{5}\right)_{2} \mathrm{C}=\mathrm{O} * \\
& \text { hydrogen abstraction: }\left(\mathrm{C}_{6} \mathrm{H}_{5}\right)_{2} \mathrm{C}=\mathrm{O} *+\mathrm{PP}-\mathrm{H} \rightarrow \quad\left(\mathrm{C}_{6} \mathrm{H}_{5}\right)_{2} \mathrm{C}-\mathrm{OH} \bullet+\mathrm{PP} \bullet
\end{aligned}
$$

(PP-H is the membrane with hydrogen on the surface, * indicates the excited state, and • indicates the radical.)

These radicals then can react with the monomer to start the desired polymer chain grafting.

initiation: $\mathrm{PP} \bullet+\mathrm{M} \rightarrow \quad \mathrm{PP}-\mathrm{M} 1 \bullet($ grafted monomer radical $)(\bullet$ indicate the radical and $\mathrm{M}$ indicates monomer)

This polymerization process can continue until the experiment is stopped or the polymerization termination occurs.

$$
\begin{array}{ll}
\text { propagation: } \mathrm{PP}-\mathrm{M}_{\mathrm{n}} \bullet+\mathrm{M} \rightarrow & \text { PP- } \mathrm{M}_{\mathrm{n}+1} \bullet(\text { grafted polymer radical) } \\
\text { termination: } \mathrm{PP}-\mathrm{M}_{\mathrm{n}} \bullet+\mathrm{H} \bullet \rightarrow \quad \mathrm{PP}-\mathrm{M}_{\mathrm{n}} \mathrm{H} \text { (grafted polymer) }
\end{array}
$$

After the photo excitation of benzophenone and hydrogen abstraction from the membrane surface, instead of direct polymerization, benzophenone can also generate a surface initiator by getting attached to the membrane surface.

$$
\left(\mathrm{C}_{6} \mathrm{H}_{5}\right)_{2} \mathrm{C}-\mathrm{OH} \bullet+\mathrm{PP} \bullet \rightarrow \quad\left(\mathrm{C}_{6} \mathrm{H}_{5}\right)_{2} \mathrm{C}-\mathrm{OH}-\mathrm{PP}(\text { surface initiator formation) }
$$

The UV irradiation can cleave the carbon-carbon bond between the membrane surface and the surface initiator forming surface radicals.

$$
\text { photoexcitation: }\left(\mathrm{C}_{6} \mathrm{H}_{5}\right)_{2} \mathrm{C}-\mathrm{OH}-\mathrm{PP}+\mathrm{UV} \rightarrow \quad\left(\mathrm{C}_{6} \mathrm{H}_{5}\right)_{2} \mathrm{OHC} \bullet+\mathrm{PP} \bullet \text { (surface radical formation) }
$$


These radicals then can react with the monomer to start the desired polymer chain grafting.

$$
\begin{aligned}
& \text { initiation: } \mathrm{PP} \bullet+\mathrm{M} \rightarrow \quad \mathrm{PP}-\mathrm{M} 1 \bullet(\text { grafted monomer radical }) \\
& \text { propagation: } \mathrm{PP}-\mathrm{M}_{\mathrm{n}} \bullet+\mathrm{M} \rightarrow \quad \mathrm{PP}-\mathrm{M}_{\mathrm{n}+1} \bullet(\text { grafted polymer radical }) \\
& \text { termination: } \mathrm{PP}-\mathrm{M}_{\mathrm{n}} \bullet+\mathrm{H} \bullet \rightarrow \quad \mathrm{PP}-\mathrm{M}_{\mathrm{n}} \mathrm{H} \text { (grafted polymer) } \\
& \mathrm{PP}-\mathrm{M}_{\mathrm{n}} \bullet++\left(\mathrm{C}_{6} \mathrm{H}_{5}\right)_{2} \mathrm{OHC} \bullet \rightarrow \quad \mathrm{PP}-\mathrm{M}_{\mathrm{n}} \mathrm{C}\left(\mathrm{C}_{6} \mathrm{H}_{5}\right)_{2} \mathrm{OH}
\end{aligned}
$$

Excited benzophenone in the solution can also get attached to a polymer chain leading to polymerization termination or take a hydrogen atom from surrounding and create $\left(\mathrm{C}_{6} \mathrm{H}_{5}\right)_{2} \mathrm{CH}-$ $\mathrm{OH}$.

Grafting yield of the polymer brush on the membrane surface using photo grafting surface modification process can depend on different factors such as the initiator concentration, monomer concentration, grafting time, and UV irradiation time [54]. Irradiation time and monomer concentration time have a linear relationship with grafting yield. Longer UV irradiation time and higher concentration of monomer are proven to produce longer and highdensity polymer chain network on the membrane surface. These dense polymer chains can act as a barrier to mass transfer across the membrane and increase the hydrophilicity of the membrane surface and membrane pores, leading to membrane wetting. Longer UV irradiation and higher monomer concentration can also lead to polymerization within the solution which can hinder the desired surface grafting. Hence, grafting thin enough hydrophilic polymer brush network using optimum UV irradiation time and monomer concentration is important. Prior surface modification studies have shown successful results using 1 wt.\% monomer concentration. Based on this knowledge, this modification process was conducted using $1 \mathrm{wt} \%$ monomer solutions in order to graft a thin enough hydrophilic layer instead of making the membrane surface entirely 
hydrophilic. Two different UV irradiation times, 5 minutes and 10 minutes, were tested in this experiment to find the optimum irradiation time.

Higher concentrations of benzophenone have been studied and proven to absorb higher percentage of the UV light hindering the polymerization. Prior studies have shown that $5 \mathrm{wt} \% \%$ of benzophenone is the ideal concentration where benzophenone is active and has the optimum use of UV light [54]. Based on this knowledge, this modification process was conducted using 5 wt.\% benzophenone solution. The modification procedure is summarized in Table 2.

Table 2. Summary of modification procedure.

\begin{tabular}{|c|c|c|c|c|}
\hline \multirow[b]{2}{*}{ Membrane } & \multicolumn{2}{|c|}{ Initiator immobilization } & \multicolumn{2}{|l|}{ UV grafting } \\
\hline & Photo initiator & Duration & Monomers & Duration \\
\hline $\begin{array}{l}\text { Polypropylene } \\
\text { (PP) }\end{array}$ & $\begin{array}{l}5 \text { wt. } \% \text { of } \\
\text { benzophenone } \\
\text { in } 30 \mathrm{~mL} \\
\text { methanol }\end{array}$ & $5 \mathrm{~min}$ & $\begin{array}{l}1 \mathrm{wt} . \% \text { of the following } \\
\text { monomers in } 5 \mathrm{~mL} \text { DI water } \\
\text { 1. HEMA } \\
\text { 2. AA } \\
\text { 3. Allyl } \\
\text { 4. Hexyl }\end{array}$ & $\begin{array}{l}5 \mathrm{~min} \\
\text { and } \\
10 \mathrm{~min}\end{array}$ \\
\hline
\end{tabular}

The surface modification of PP membranes was carried out in a two-step process as reported in the literature [51]. The membranes were dipped in methanol containing 5 wt.\% benzophenone. The methanol was used to swell the membrane allowing benzophenone to enter the membrane matrix $[55,56] \cdot$ Then the membrane was air dried for 12 hours trapping benzophenone inside the membrane matrix or on top of the membrane surface. In the second step, the aqueous solution (1 wt.\%) of the monomers (HEMA, AA, allyl and hexyl) were poured 
on top of the membrane and exposed to UV irradiation $(160 \mathrm{~W})$. Due to the limited penetration depth of UV light, only the benzophenone trapped on membrane surface will initiate the radicals and the subsequent radical coupling with monomer molecules resulting in growth of hydrophilic polymers [16].

After the polymerization process the modified membranes were washed using $50 \%$ ethanol-water solution to remove unreacted benzophenone and non-grafted polymer chains. The polymer chain length may be varied by varying the UV irradiation times.

\subsubsection{Membrane characterization}

Fourier-transform infrared spectroscopy (FTIR) was used to identify the presence of the functional groups on the membrane surface using IR Affinity (Shimadzu, Columbia, MD, USA) with a horizontal ZnSe accessory. The membrane samples were dried overnight prior to FTIR analysis.

Water contact angles were measured using a sessile drop contact angle goniometer (Model 100) procured from Rame-Hart Instrument Company, Netcong, NJ. A $5 \mu \mathrm{L}$ deionized water droplet was formed at a rate of $1 \mu \mathrm{L} / \mathrm{s}$, which was then moved down vertically towards the membrane to make contact with the membrane surface. The droplet was detached from the micro syringe by moving it up and the DI water drop was placed on the membrane surface. The angle made between the water droplet and the membrane surface was measured using the circle fitting method.

Scanning electron microscopy (SEM) images and energy dispersive x-ray spectroscopy (EDX) results were obtained using a Nova Nanolab 200 Duo-Beam Workstation (FEI, Hillsboro, Oregon) to analyze membrane surface before and after MD. 


\subsubsection{Direct Contact Membrane distillation (DCMD)}

Figure 2 is a schematic diagram of the DCMD system used. The membrane was placed in between the two plates of the module. There was a spacer placed between the module and membrane surface to ensure uniform flow distribution of the feed solution on the membrane surface. The effective surface area of the membrane was $40 \mathrm{~cm}^{2} .1 \mathrm{~L}$ of PW was used as the feed at $60{ }^{\circ} \mathrm{C}$. The temperature of the distillate side was maintained at $10{ }^{\circ} \mathrm{C}$ using a chiller. The mass transferred from the feed side to the distillate was determined every 5 minutes by checking different readings of the balance which was connected to a computer. Two peristaltic pumps were used to maintain a flow rate of $500 \mathrm{~mL} / \mathrm{min}$ on both feed and distillate side in counter current flow. A conductivity meter was used to determine the conductivity of the distillate side.

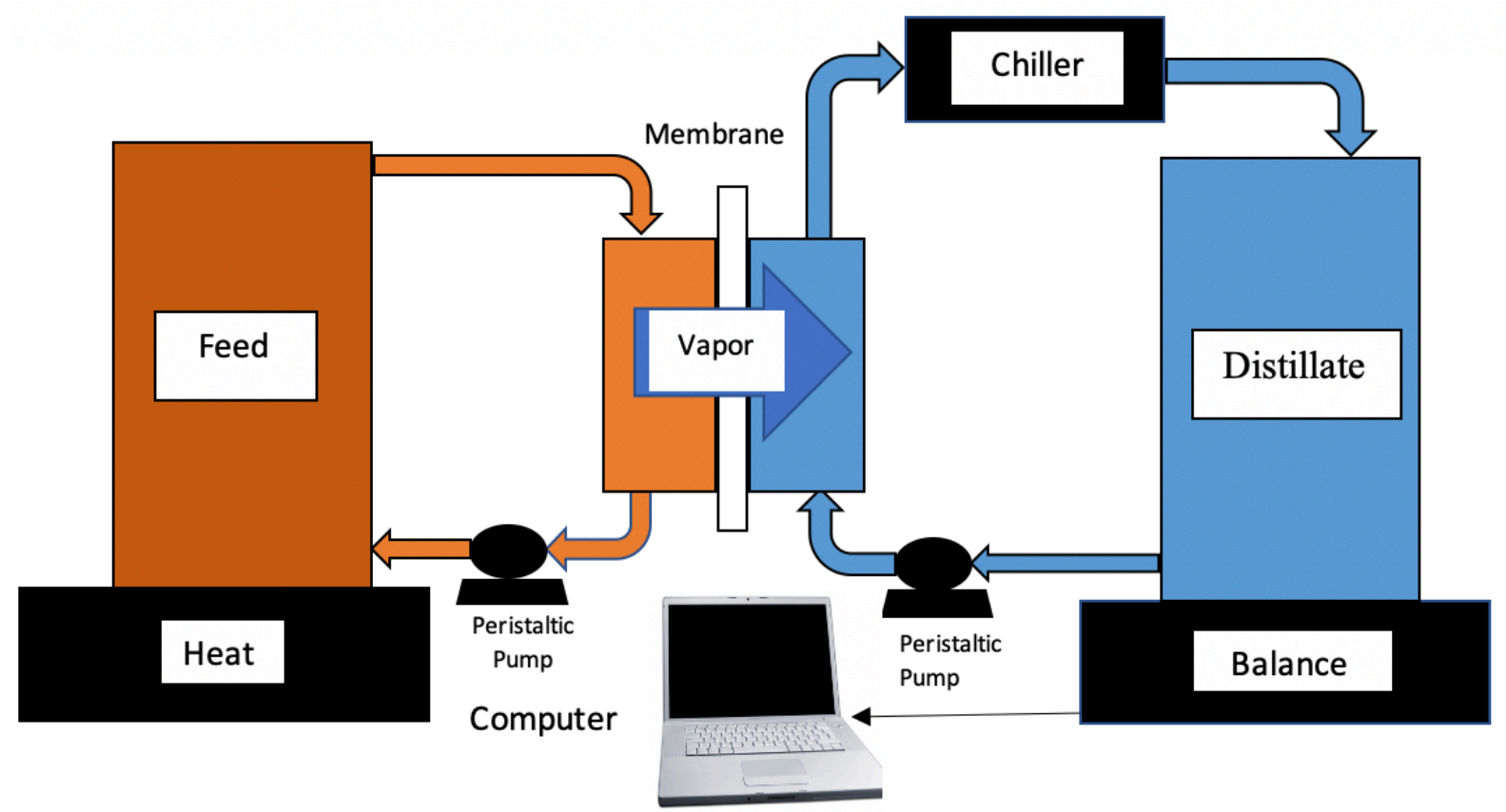

Figure 2. Schematic diagram of the DCMD set up. 
The flux was calculated as follow[8].

$$
\mathrm{J}_{\mathrm{w}}=\frac{\Delta \mathrm{m}}{\mathrm{At}}
$$

Where, $J_{\mathrm{w}}$ is the distillate flux $\left(\mathrm{g} / \mathrm{m}^{2} \mathrm{~h}\right), \Delta \mathrm{m}$ is mass transferred to distillate during the time step $(\mathrm{g}), \mathrm{A}$ is the effective membrane surface area $\left(\mathrm{m}^{2}\right)$ and $\mathrm{t}$ is the time step $(\mathrm{h})$. In the investigation, PP membrane with an effective surface area $7.5 \mathrm{~cm} \times 12.5 \mathrm{~cm}$ with average pore size $0.2 \mu \mathrm{m}$ was used. $\mathrm{J}_{\mathrm{w}}$ was converted to $\mathrm{L} / \mathrm{m}^{2} \mathrm{~h}$, here referred to as $\mathrm{LMH}$, using the density of water of 1 $\mathrm{g} / \mathrm{cm}^{3}$. After operation, both sides of the membrane were flushed with DI water at room temperature for one hour.

Table 3 gives the different feed waters tested with different membranes. After DCMD, DI water was pumped on both sides of the membranes in counter current flow to remove rejected species from the membrane surface prior to running the next DCMD cycle. Each DCMD run was continued until $500 \mathrm{~mL}$ of distillate, $50 \%$ water recovery, was obtained. The run was stopped before this target was reached if flux decline led to very low fluxes or the conductivity of the permeate increased above $50 \mu \mathrm{S} / \mathrm{cm}$ indicating pore wetting and, hence, membrane failure. The feed temperature was always maintained at $60^{\circ} \mathrm{C}$ and all the experiments were conducted in batch mode. Distillate temperature was maintained at $10^{\circ} \mathrm{C}$.

Table 3. Summary of DCMD experiments.

\begin{tabular}{|l|l|l|}
\hline Feed & Membrane & Duration \\
\hline PW & Base and modified membranes & $\begin{array}{l}\text { Until 500 ml distillate was } \\
\text { collected or flux decline lead to } \\
\text { very low fluxes or rapid increase } \\
\text { in conductivity indicated pore } \\
\text { wetting. After each run } \\
\text { membranes were flushed with DI } \\
\text { water and reused. }\end{array}$ \\
\hline Synthetic PW & $\begin{array}{l}\text { Base and allyl modified } \\
\text { membrane }\end{array}$ & $\begin{array}{l}\text { Base and allyl modified } \\
\text { membrane }\end{array}$ \\
\hline EC pretreated PW
\end{tabular}




\subsubsection{Electrocoagulation}

Electrocoagulation (EC) was conducted using sacrificial aluminum electrodes as described in earlier publications [8,9]. The EC setup used in this experiment was designed with a $600 \mathrm{~mL}$ polycarbonate reactor consisting of five electrodes. 6061 aluminum alloy (Sapa, Rosemont, IL) with effective surface area of $180 \mathrm{~cm}^{2}$ aluminum electrodes were set up vertically with an $8 \mathrm{~mm}$ space between each electrode where the electrodes at each end were connected to the DC power source (Hewlett Packard, Palp Alto, CA) as the cathode and anode. EC pretreatment process was conducted in batch mode for $30 \mathrm{~s}$ with a $0.5 \mathrm{~A}$ constant current. Electrocoagulated sample was then moved to a separatory funnel for sedimentation and the clear water sample was recovered after $6 \mathrm{~h}$ sedimentation time. 


\section{Results and discussion}

\subsection{Surface modification}

The swelling of PP membrane in the presence of methanol was used to trap the benzophenone. Benzophenone is a type 2 photoinitiator [57,58]. In presence of UV irradiation, the carbonyl group of benzophenone is activated and, subsequently, abstract protons from the PP membrane by hemolytic cleavage of $\mathrm{C}-\mathrm{H}$ bond generating radicals as shown in Figure 3 . These radicals, thus generated, attack the $\pi$ bonds of the monomer. The hemolytic cleavage of the $\pi$ bonds result in the formation of covalent bonds between the PP membrane and the monomer, leaving a carbon based radical on the monomer. This radical can attack another monomer in the same fashion leading to chain propagation. Alternatively, chain termination occurs when a proton is captured from the environment or chain coupling occurs [54]. The duration of UV and the relative concentration of the precursors influence the relative yield of the products.

\subsection{Characterization}

\subsubsection{Fourier-transform infrared spectroscopy (FTIR)}

FTIR spectra for the modified and unmodified membranes are given in Figure 4.

The spectrum for the virgin membrane showed peaks corresponding to $\mathrm{C}-\mathrm{H}$ and $\mathrm{CH}_{2}$ bend $/ \mathrm{CH}_{3}$ deformation [59]. The spectra for HEMA and AA modified membranes showed a clear peak from the carbonyl bond $\sim 1735 \mathrm{~cm}^{-1}[60,61]$. The exact peak positions for these two carbonyl peaks were slightly shifted, since the carbonyl from HEMA is of ester origin while the carbonyl of AA is of carboxylic origin. Both membranes also showed a broad peak near $3200-3500 \mathrm{~cm}^{-1}$, which was attributed to the hydroxyl group engaged in hydrogen bonding.

PIL grafted membranes exhibit prominent peaks from imidazolium stretching. Figure 4 shows the FTIR spectra for 5 and 10 min UV reaction times. Figure 5 shows additional spectra 


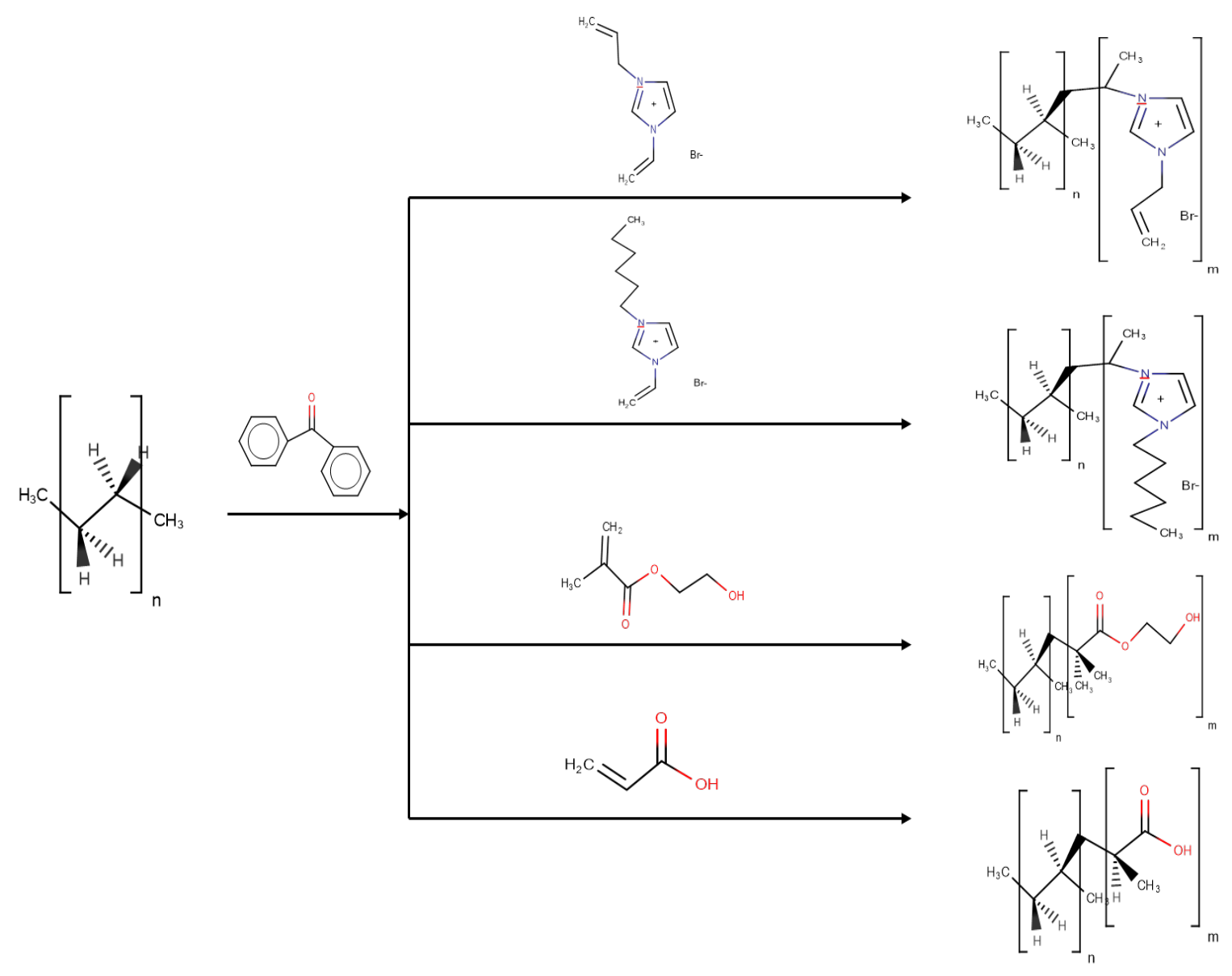

Figure 3. Modification of PP membrane by HEMA, AA, allyl and hexyl-based monomers.

where no monomer was present during UV irradiation. Consequently, this represented a negative control as no reactant was present. The spectra did not show any additional peaks after irradiation, as expected. Figure 6,7,8 and 9 compares spectra for 5- and 10-min UV reaction times. As expected, stronger peaks related to the grafted polymer were observed for longer polymerization times indicating longer polymer chains.

\subsubsection{Contact Angle}

Water contact angles are given in Table 4. The base PP membrane showed a water contact angle 


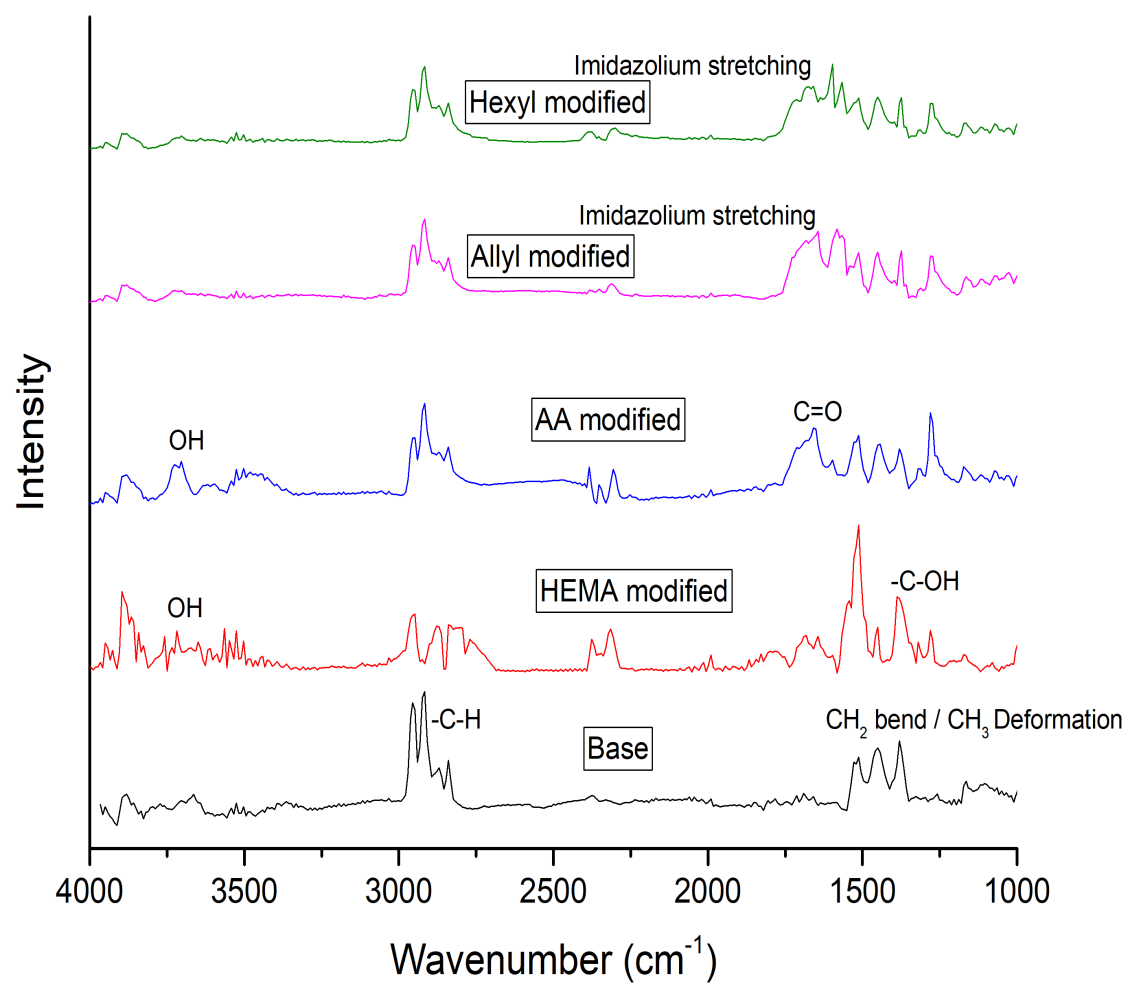

Figure 4. FTIR spectra for the modified membranes.

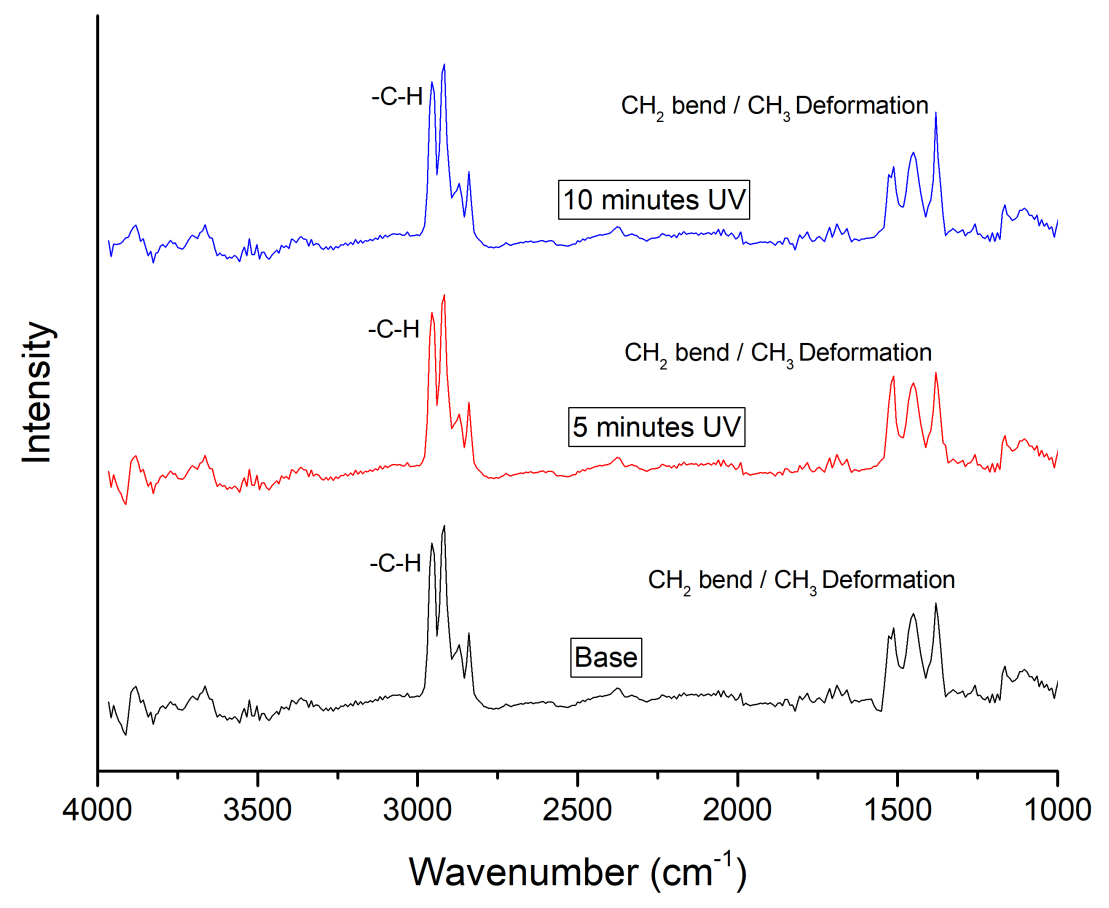

Figure 5. FTIR spectra for the modified membranes using water. 


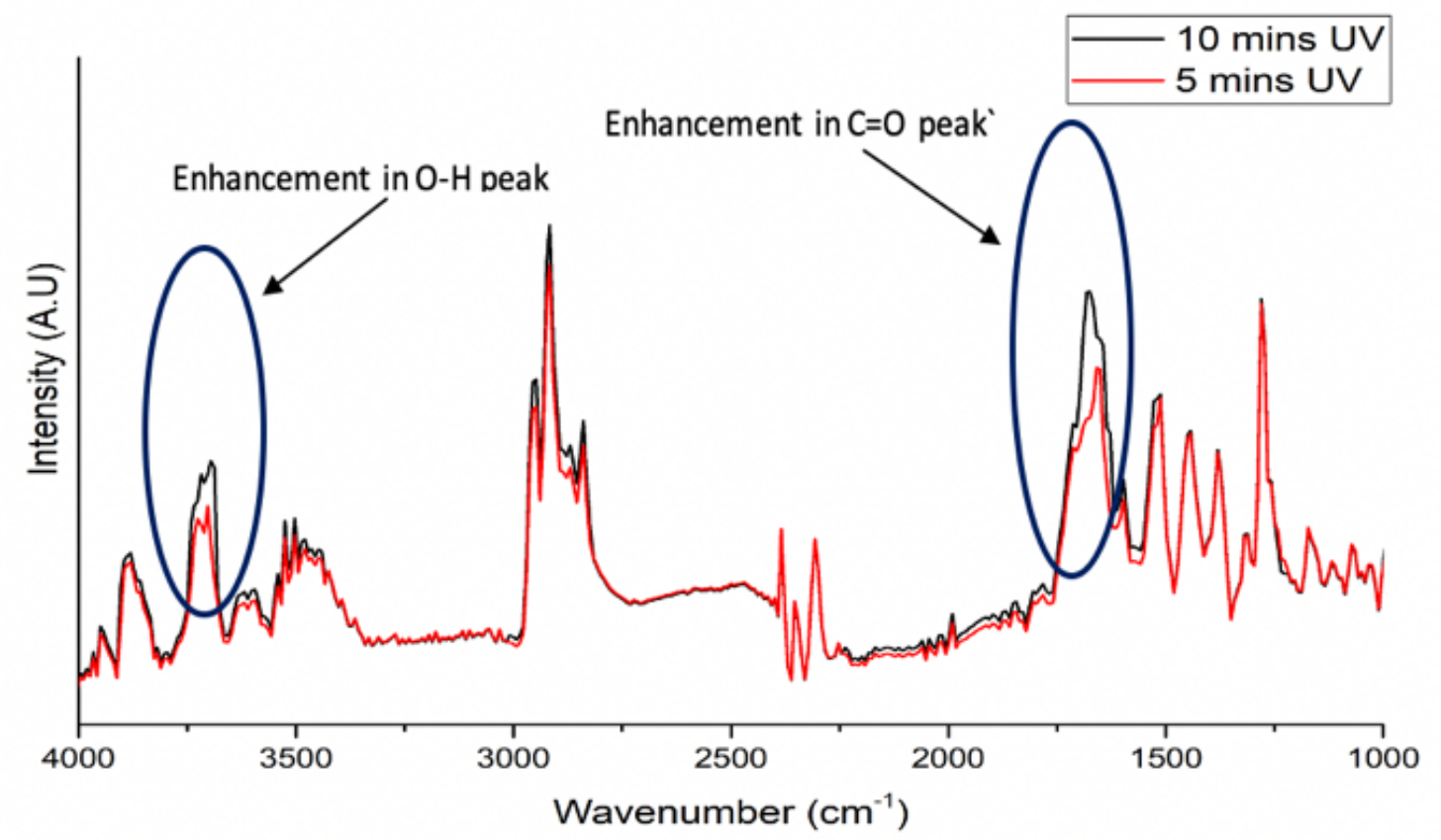

Figure 6. Enhancement of carbonyl peak intensity for HEMA modified membranes at different UV time.

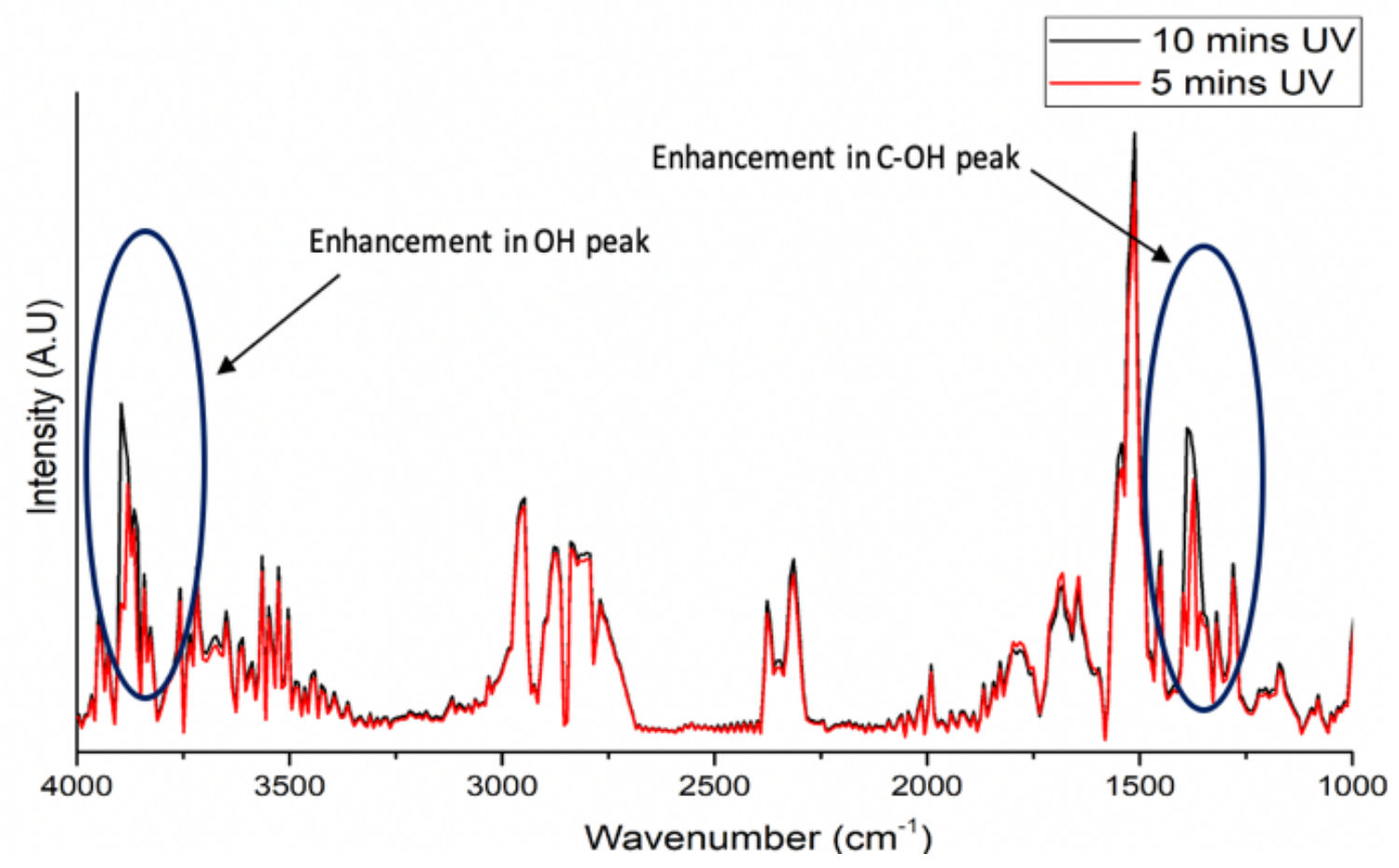

Figure 7. Enhancement of carbonyl peak intensity for AA modified membranes at different UV time. 


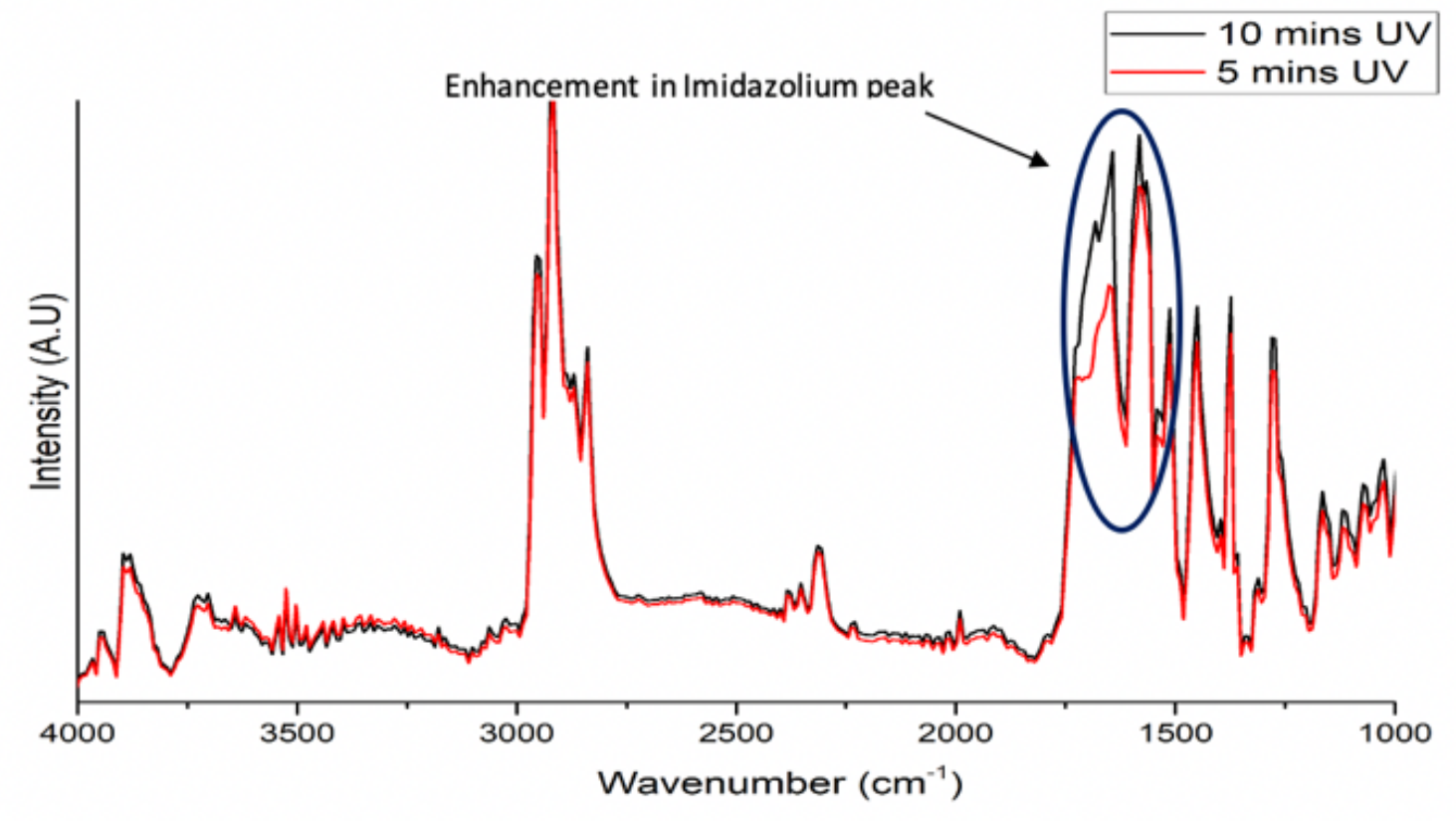

Figure 8. Enhancement of imidazolium peak intensity for allyl modified membranes at different UV time.

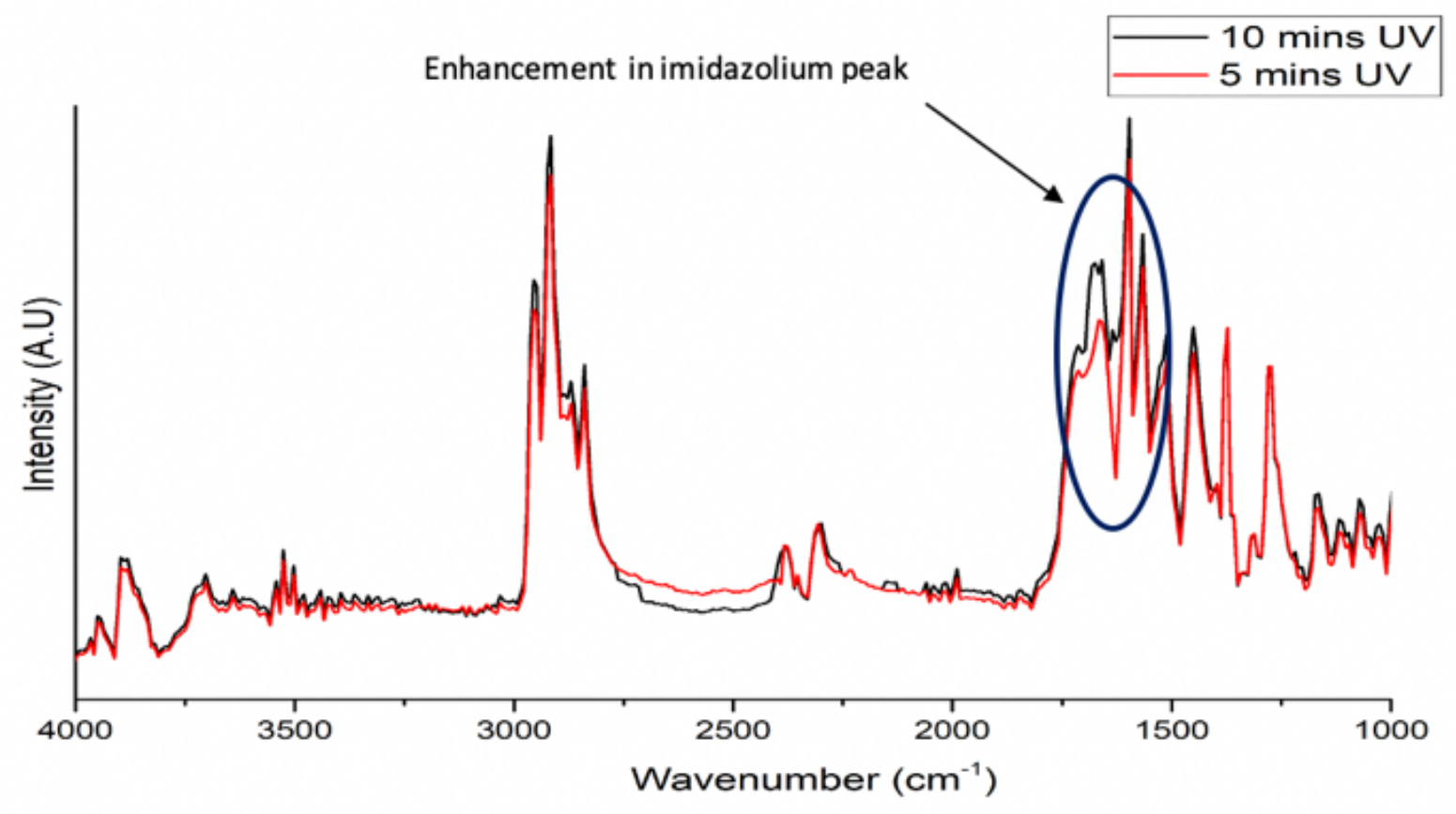

Figure 9. Enhancement of imidazolium peak intensity for bromo modified membranes at different UV time. 
of $130^{\circ}$, indicating the membrane was hydrophobic [62]. Though the water contact angles decrease for all polymer modifications; the membranes remain rather hydrophobic. Increased polymerization time suggested a decrease in contact angle though, in all cases, the results were within the measurement variability. Table 5 shows water contact angle for irradiation in the absence of monomer. The data show that the contact angle of the PP membrane did not change indicting no modification as expected.

Table 4. Water contact angles for the modified membranes obtained from different UV exposure (average of five experiments conducted with ph 6 DI water)

\begin{tabular}{|c|c|c|c|c|c|}
\hline \multirow{2}{*}{$\begin{array}{l}\text { PP Base } \\
\text { membrane }\end{array}$} & \multirow{2}{*}{$\begin{array}{c}\text { UV grafting } \\
\text { time } \\
\text { (minutes) }\end{array}$} & \multicolumn{4}{|c|}{ Modified PP Membranes } \\
\hline & & HEMA & AA & Allyl & Hexyl \\
\hline \multirow[t]{2}{*}{$130^{\circ} \pm 2^{\circ}$} & 5 & $107^{\circ} \pm 3^{\circ}$ & $112^{\circ} \pm 1^{\circ}$ & $107^{\circ} \pm 3^{\circ}$ & $106^{\circ} \pm 4^{\circ}$ \\
\hline & 10 & $106^{\circ} \pm 3^{\circ}$ & $110^{\circ} \pm 3^{\circ}$ & $104^{\circ} \pm 2^{\circ}$ & $103^{\circ} \pm 4^{\circ}$ \\
\hline \multicolumn{6}{|c|}{ Fouled membrane } \\
\hline $85^{\circ} \pm 2^{\circ}$ & 5 & $70^{\circ} \pm 2^{\circ}$ & $79^{\circ} \pm 2^{\circ}$ & $65^{\circ} \pm 2^{\circ}$ & $68^{\circ} \pm 2^{\circ}$ \\
\hline
\end{tabular}

Table 5. The water contact angles for the modified membranes using water.

\begin{tabular}{|c|c|c|}
\hline PP Base membrane & $\begin{array}{c}\text { UV grafting time } \\
\text { (minutes) }\end{array}$ & Modified PP Membranes using water \\
\hline $130^{\circ} \pm 2^{\circ}$ & 5 & $130^{\circ} \pm 3^{\circ}$ \\
\cline { 2 - 3 } & 10 & $127^{\circ} \pm 2^{\circ}$ \\
\hline
\end{tabular}

\subsection{Membrane Performance}

The variation of distillate flux with distillate volume for $5 \mathrm{~min}$ polymerization time is shown in Figure 10 (a). In all cases, the conductivity of the distillate never rose above $50 \mu \mathrm{Scm}^{-1}$. Thus, membrane failure and pore wetting did not occur. All experiments were stopped when the targeted 50\% recovery was achieved except for the base membrane. For the base membrane, a rapid decline in flux was observed. Consequently, the experiment was stopped before $50 \%$ or $500 \mathrm{~mL}$ of distillate was collected. For modified membranes, the highest flux was obtained for 
allyl modification and was followed by hexyl, AA, and HEMA modifications.

Figure $10(\mathrm{~b})$ gives analogous results for $10 \mathrm{~min}$ polymerization times. This time, $50 \%$ water recovery was only possible for allyl and hexyl modified membranes. As well as the base membrane, HEMA and AA modified membranes exhibited very rapid flux decline. However, for all membranes, the flux decreased much more rapidly than for 5 min polymerization times.

Nevertheless, pore wetting was not observed as the conductivity of the permeate did not increase above $50 \mu \mathrm{Scm}-1$. In order to determine membrane stability, DI water was pumped on either side of the membrane and then DCMD conducted again.
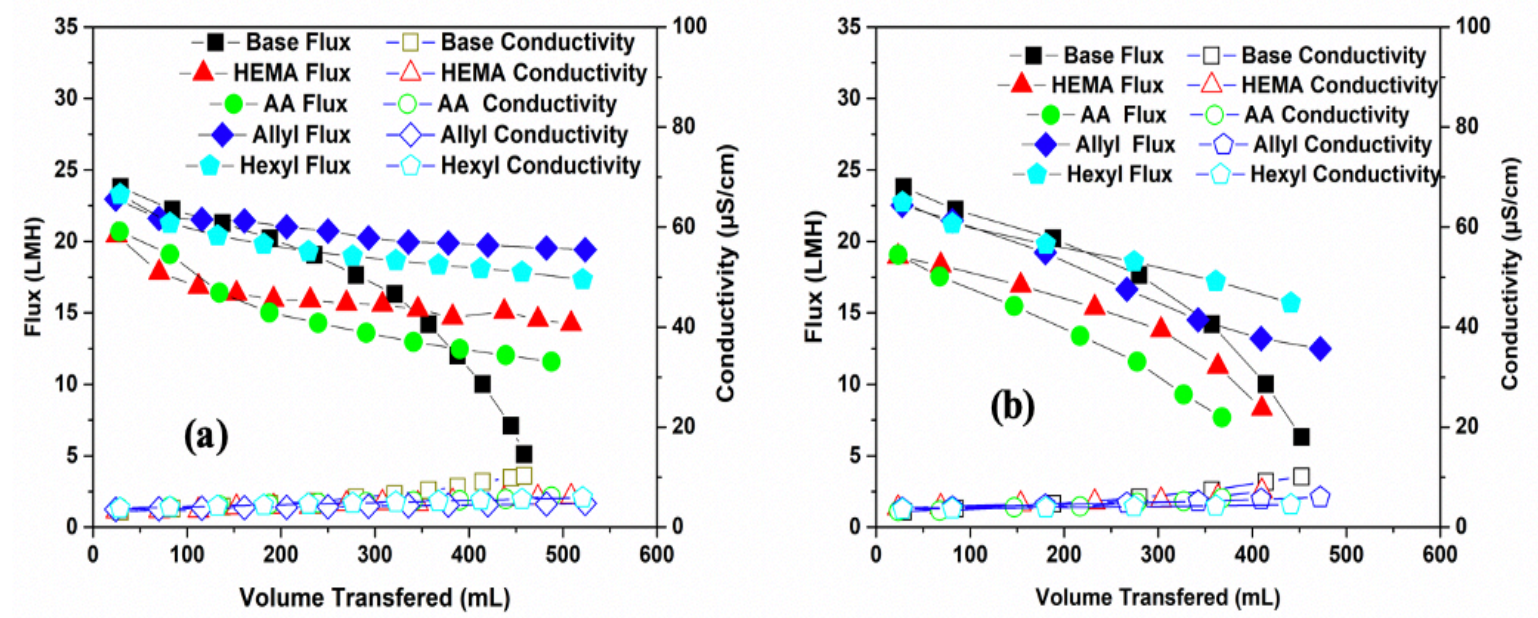

Figure 10. Variation of flux with distillate volume for modified membranes obtained by (a) 5 min UV grafting; (b) 10 min UV grafting. The feed stream was PW.

Figures 11-15 indicate that only the allyl and hexyl modified membranes could be run three times for 5 min polymerization times. Base, HEMA, and AA modified membranes displayed very rapid flux decline, thus $50 \%$ water recovery was not possible. Further, during the second run for the AA modified membrane and the third run for the base and HEMA modified 
membranes, the membranes failed leading to pore wetting and a rapid increase in conductivity. For the allyl and hexyl modified membranes, the flux steadily decreased for each successive run. The allyl modified membrane outperformed the hexyl modified membrane.

Figure 10 as well as Figures 11-16 indicate that for 10 min polymerization times, the membrane performance was worse. Taken together, these results suggested that the presence of repeating fixed charges on the grafted polymer chains was desirable and increased membrane stability. In addition, thicker grafted nanolayers could promote pore wetting during operation.

Table 4 gave the contact angle for fouled membranes ( 5 min polymerization time) while Figure 17 gives the FTIR spectra. For allyl and hexyl modified membranes, this was after three DCMD runs. For the base and HEMA modified membranes, this was after pore wetting occurred during the third DCMD run, while for the AA modified membrane, it was after pore wetting occurred during the $2^{\text {nd }}$ DCMD run.

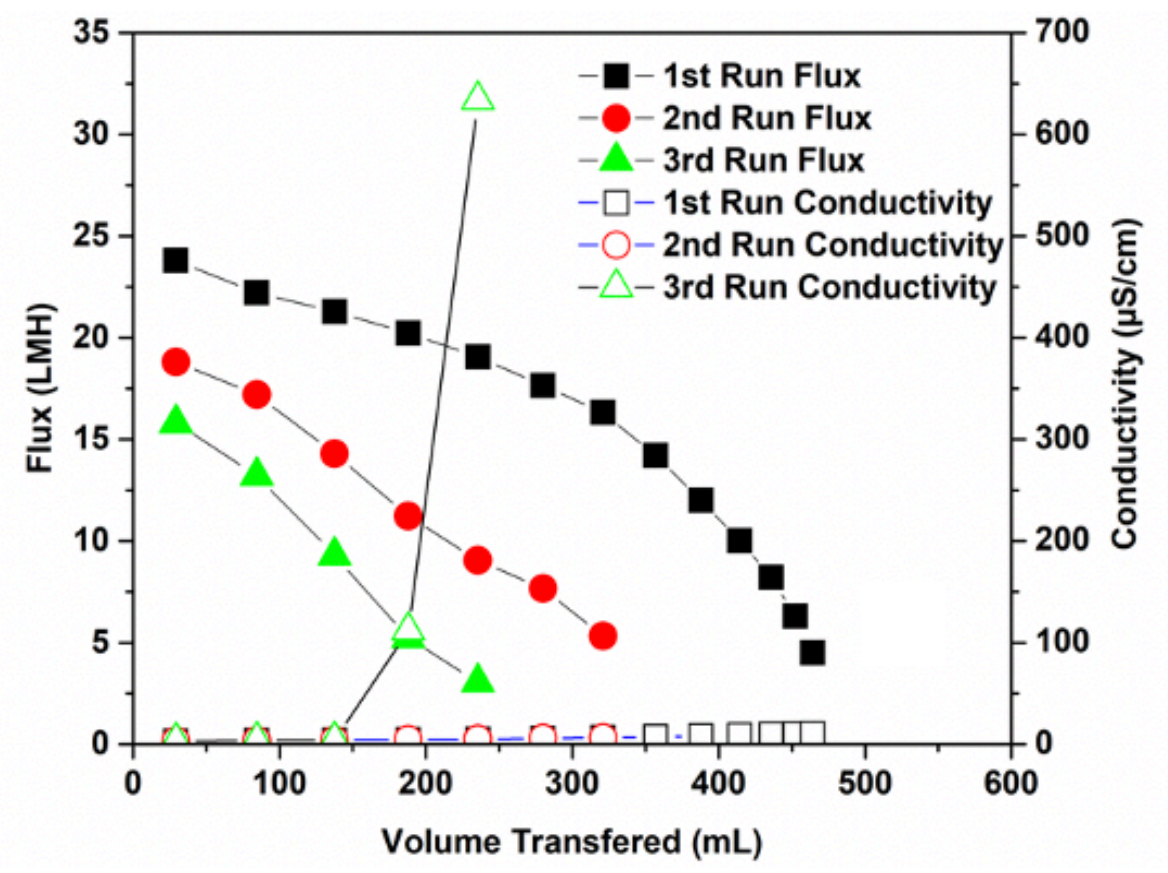

Figure 11. Flux versus distillate volume for consecutive MD cycles: base PP membrane. 


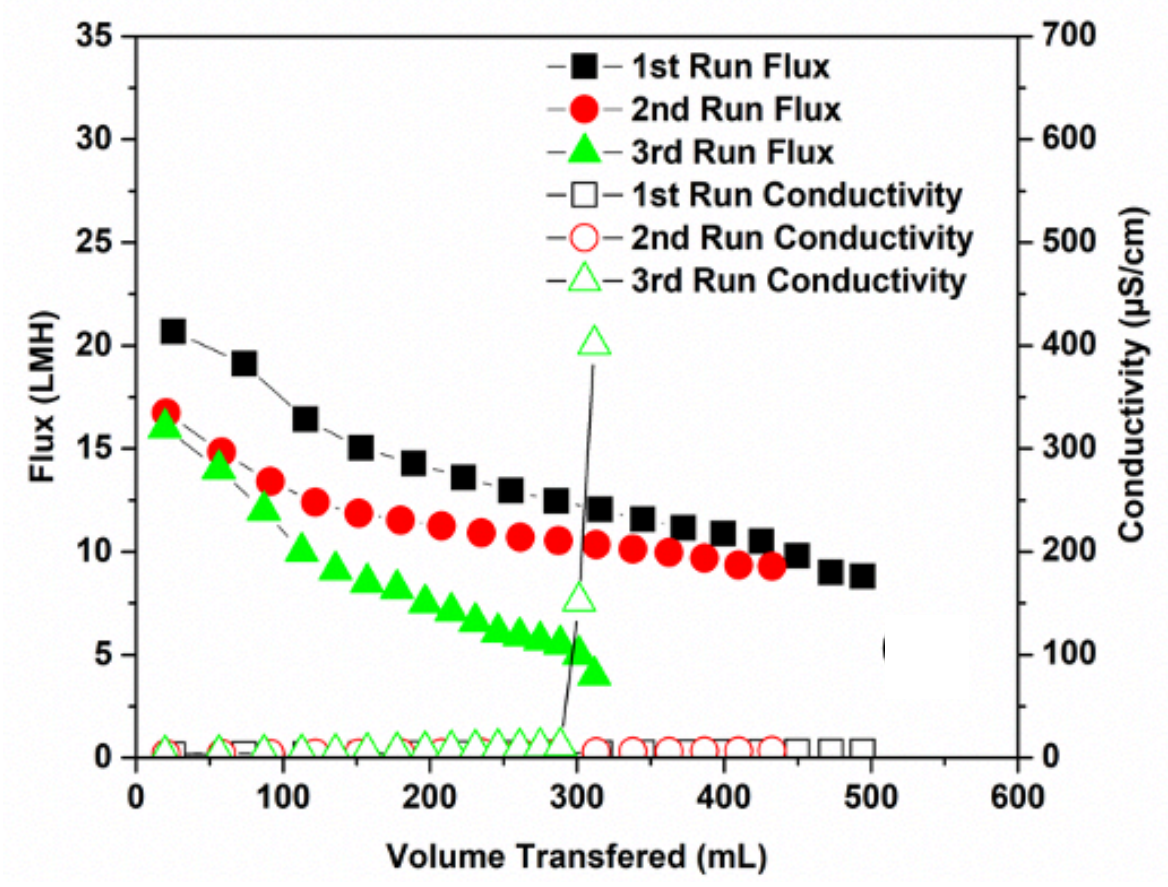

Figure 12. Flux versus distillate volume for consecutive MD cycles: HEMA modified membrane.

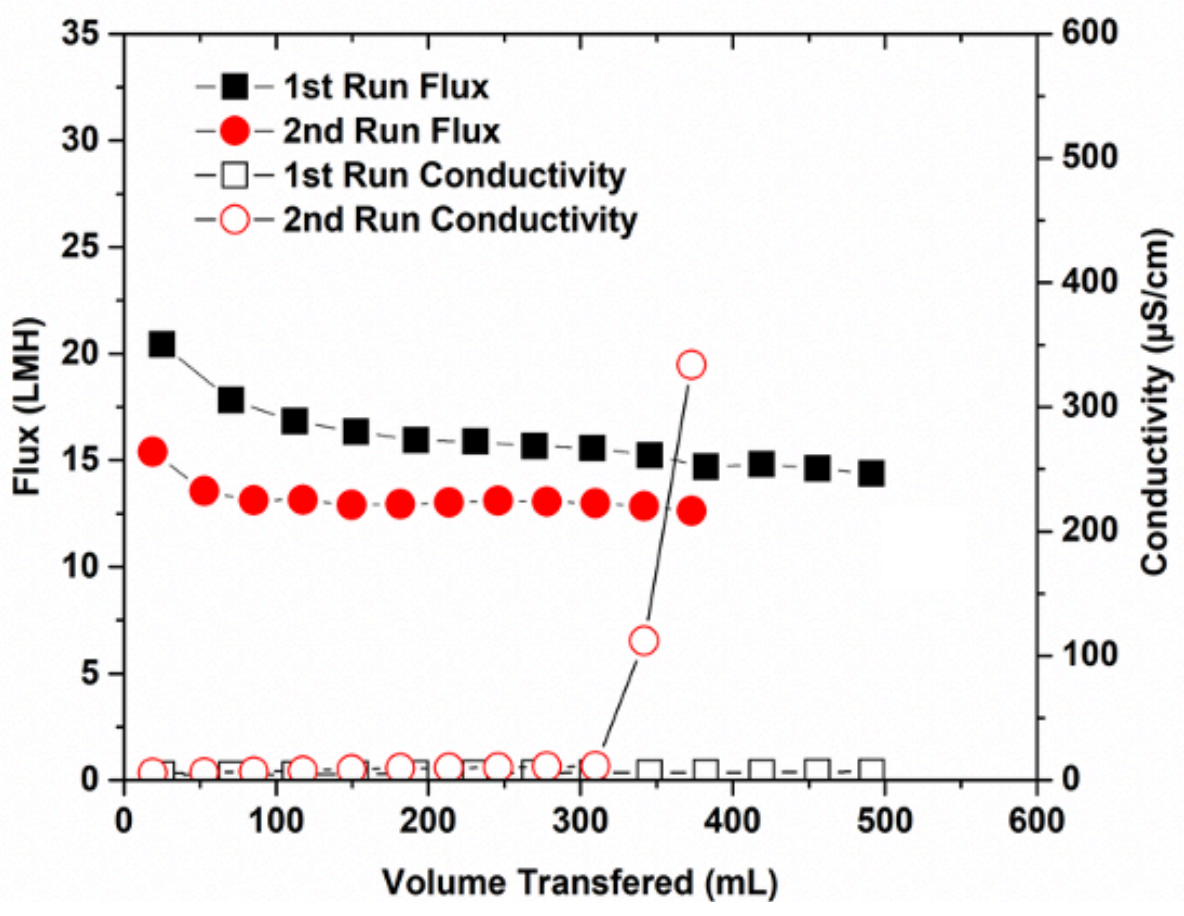

Figure 13. Flux versus distillate volume for consecutive MD cycles: AA modified membrane. 


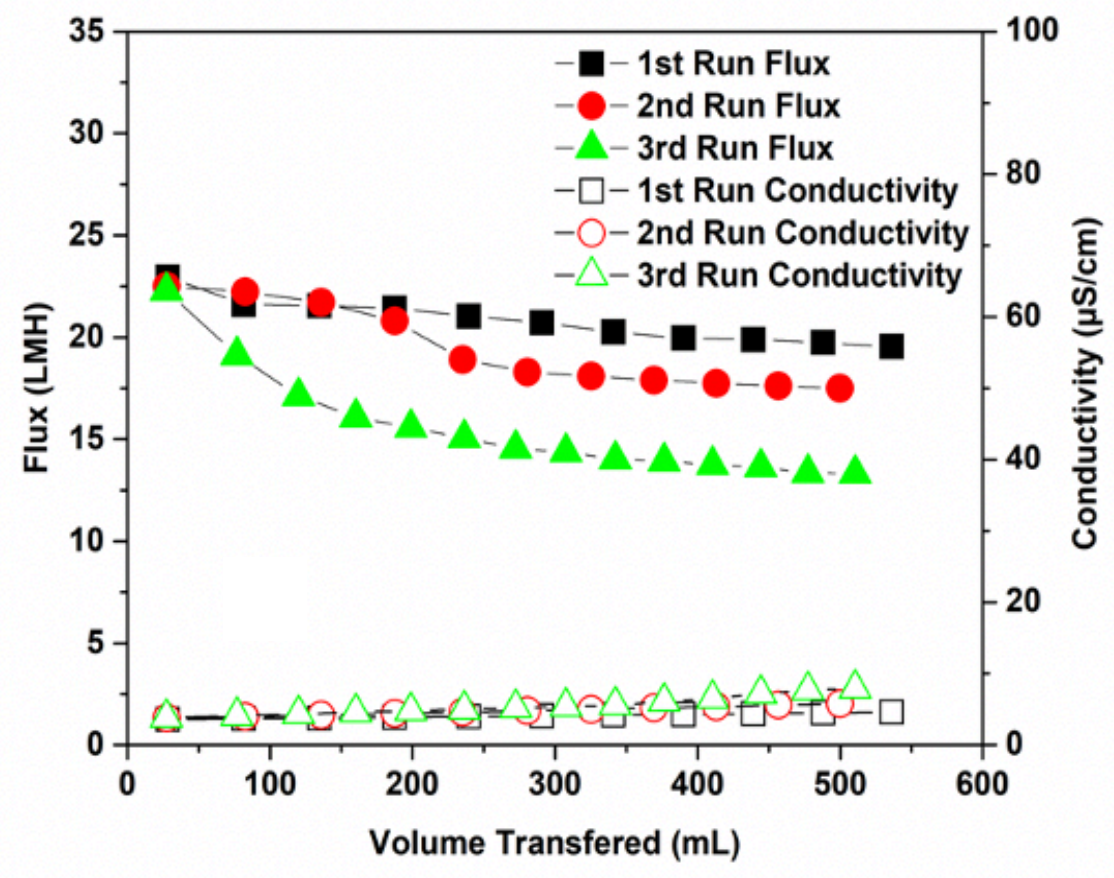

Figure 14. Flux versus distillate volume for consecutive MD cycles: allyl modified membrane.

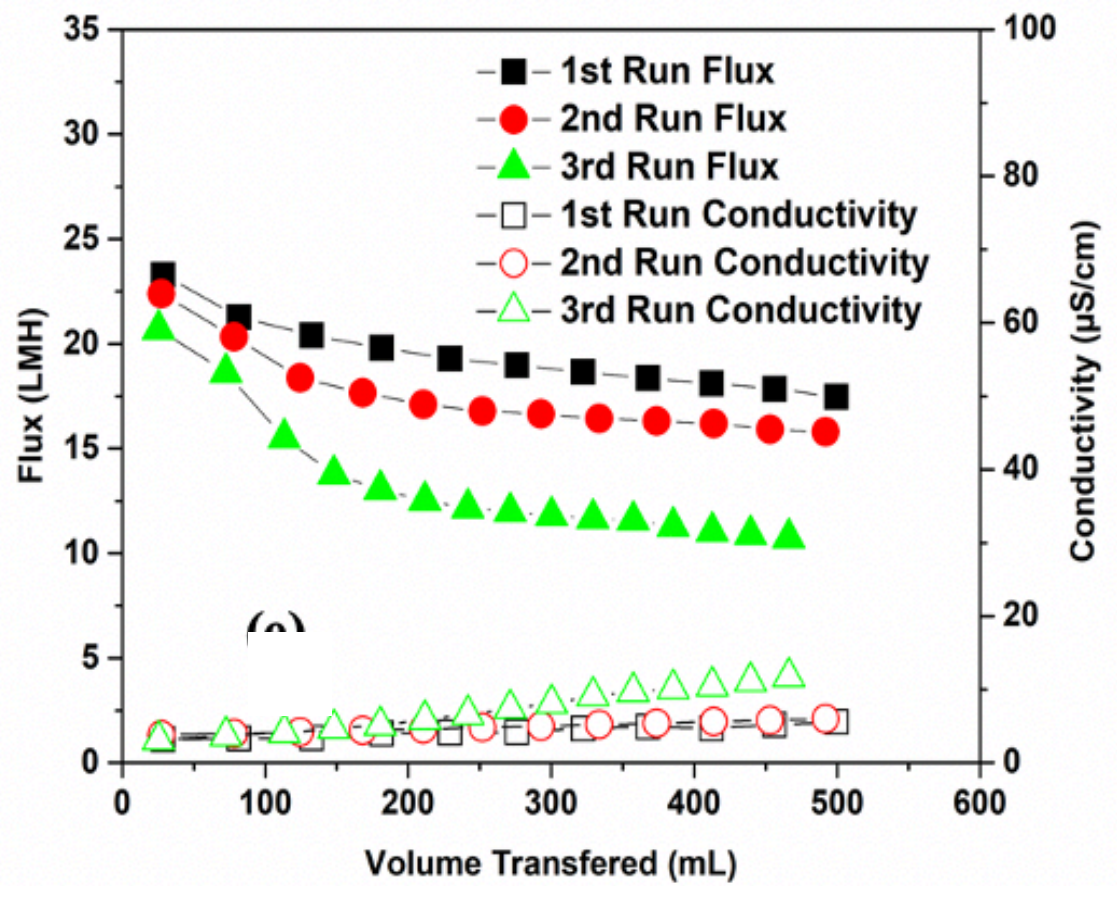

Figure 15. Flux versus distillate volume for consecutive MD cycles: hexyl modified membrane. 


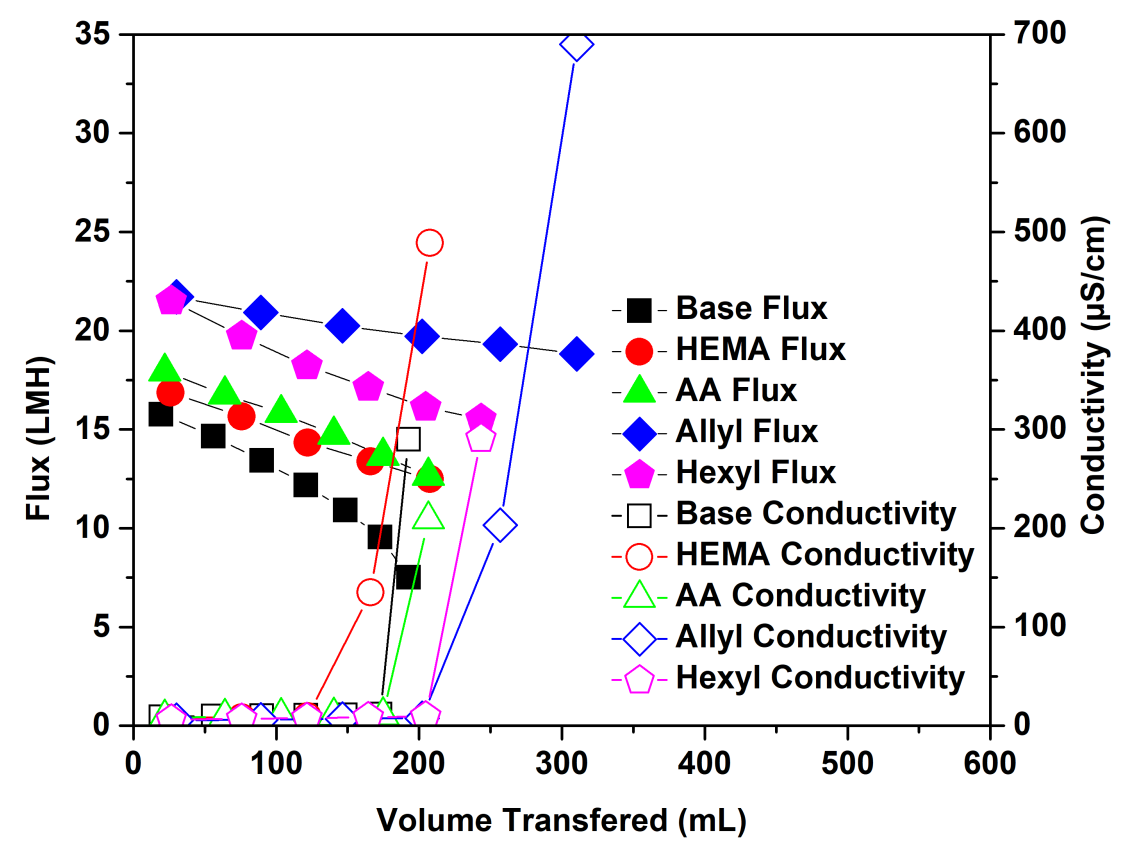

Figure 16. The flux versus distillate volume transfer for 2 nd MD cycle using modified PP membranes ( 5 min benzophenone, $10 \mathrm{~min}$ UV).

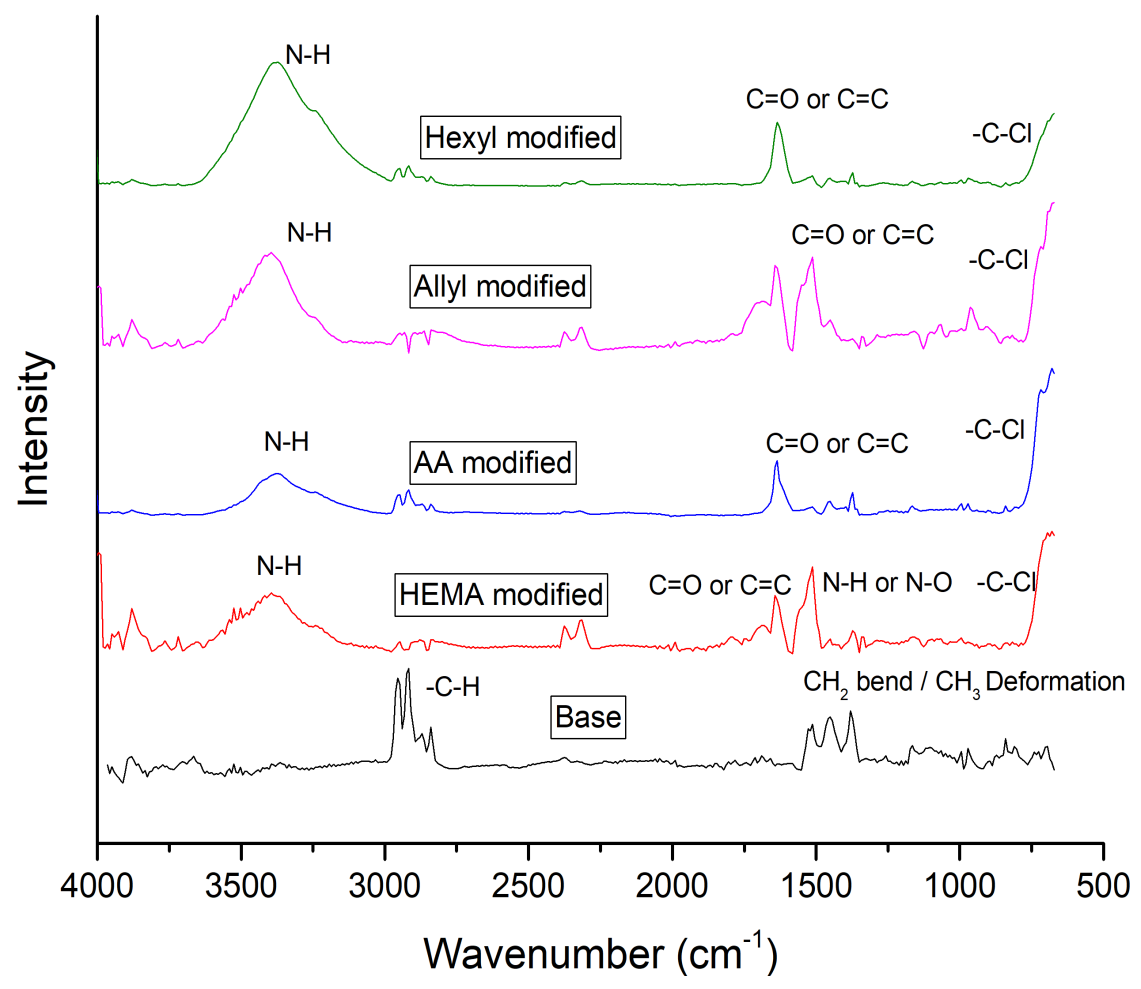

Figure 17. FTIR spectra of fouled membranes after processing PW by DCMD. 
Comparing the results to the membrane prior to DCMD, a significant decrease in contact angle was observed. The results clearly indicated that the adsorption of rejected species led to a change in surface properties of the membrane. However, it is interesting to note that the greatest decrease in contact angle occurred for the allyl and hexyl modified membranes, though those membranes displayed the greatest resistance to failure due to pore wetting. The reduction in contact angle suggested the hydrophilic nature of the fouled surface. Due to the complex nature of the feed stream (containing dissolved inorganic as well as organic species), it was the interplay between the interactions of these species and the membrane surface properties, that determined membrane performance. Given the $\mathrm{pH} 7.74$ of $\mathrm{PW}$ and the $\mathrm{pKa}$ for the first deprotonation of the polyAA chain was 4.2 , the poly AA chains were expected to be charged [63]. It can be seen that polyAA chains gave the lowest distillate flux even though the chains were charged (Figures 11-15). The initial flux values for modified membranes were found to be slightly lower compared to the virgin membrane. The presence of a grafted nanostructure on the surface of the membrane will lead to an increase in the resistance to flow through the membrane. These results suggest that for both the base and modified membranes, organic compounds present in the PW were adsorbing onto the membrane surface leading to flux decline and eventual membrane failure.

FTIR spectra provided insight into the organic species that were adsorbed onto the membrane surface. Appearance of peak $\sim 1700 \mathrm{~cm}^{-1}$ in all the fouled membranes could be attributed to either carbonyl moieties of different kinds (keto, aldehyde, ester, carboxylic acid etc.) or alkene moieties. The fouled membranes also showed the appearance of $-\mathrm{NH}$ moieties corresponded to amine groups (primary or secondary) on the surface. C-O and C-Cl stretching frequency were also observed. Those changes were due to deposition of organic species on the 
membrane surface. In particular, the appearance of $\mathrm{N}$ and $\mathrm{O}$ could explain the decrease in contact angle for fouled membranes.

Since the allyl modified membranes using a 5 min UV reaction time gave the best performance, it was investigated further. Results for the allyl modified membrane were compared to the base PP membrane. Both membranes were challenged with two additional feed streams, synthetic PW that contained sodium, calcium, and chloride (the main inorganic constituents of the PW) as well as PW after EC. Earlier work indicated that pretreatment with EC under the conditions used led to reduction in $91 \%$ TSS, $61 \%$ TOC and $96 \%$ turbidity $[8,9]$. The variation of flux with distillate volume is given in Figure 18 after the first DCMD run.

Figure 18 indicates that the highest fluxes were obtained for the synthetic PW. The fluxes for the base and allyl modified membranes were similar. The slightly lower flux for the

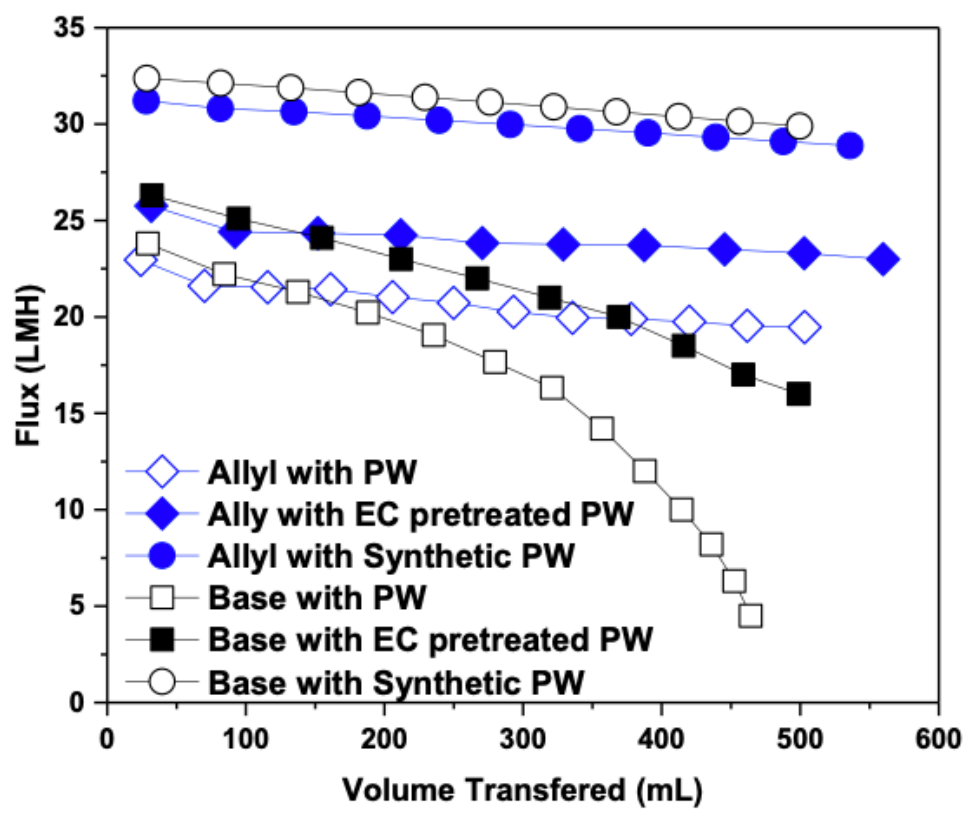

Figure 18. Variation of flux with distillate volume for allyl and base PP membranes. Results are given for PW, EC pretreated PW, and synthetic PW. 
allyl modified membrane may have been due to the additional resistance to water transport due to the grafted barrier layer. Pretreatment with EC led to an improved flux compared to nonpretreated PW. However, the synthetic PW gave the highest fluxes. These results indicate that it was the presence of organic species and most likely polar organic species (hence the decrease in contact angle) that resulted in the decrease in permeate flux. The allyl modified membrane displayed higher fluxes for both PW and EC pretreated PW. The result suggested that the allyl modification reduced adsorption of organic compounds.

In order to further analyze the nature of the adsorbed layer on the membrane surface, SEM images were taken and EDX analysis was conducted for the base sand allyl modified membranes. SEM images are shown in Figure 19 while the result of EDX analysis are given in Table 6. The SEM images provide qualitative agreement with the flux result given in Figure 10. Significant fouling was observed for the base and allyl modified membranes challenged with PW. While the EC pretreated PW showed some deposition on the membrane surface, the synthetic PW showed the least adsorption.

The EDX data indicated that for the base and the allyl modified membranes (Table 6), O and $\mathrm{N}$ atoms were detected. As the base PP membrane did not contain any $\mathrm{N}$, those results indicated the fouling of base membrane occurred due to organic compounds present in the PW. EDX data for the base membrane with synthetic PW and EC pretreated PW did not indicate presence of $\mathrm{N}$ providing more evidence that fouling occurred by adsorption of organic compounds in the PW.

For PW, both the base and allyl modified membranes indicated adsorption of organic compounds (increase in $\mathrm{O}$ and $\mathrm{N}$ ) which agrees with the FTIR spectra (Figure 17). The appearance of $\mathrm{O}$ peak more likely revealed the presence of $\mathrm{O}$ containing organic matter on the 
membrane surface, while the other peaks might have been due to the deposition of salts like

$\mathrm{NaCl}, \mathrm{CaCl}_{2}, \mathrm{FeCl}_{3}$, etc. present in PW in terms of TDS. The EDX showed a prominent presence of $\mathrm{Na}, \mathrm{Ca}$, and $\mathrm{Cl}$ peaks corresponding to the deposition of salt on the membrane surface.
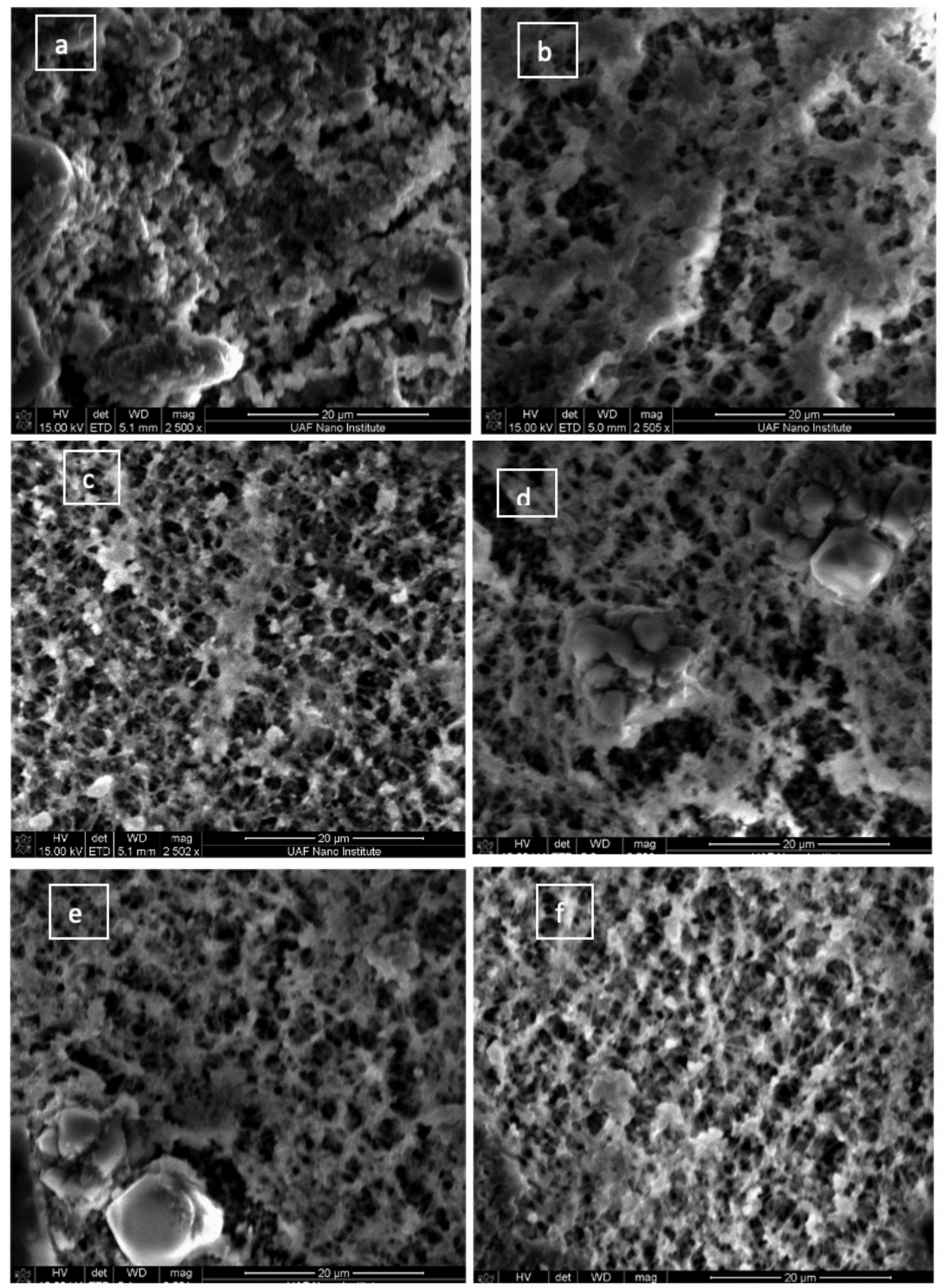

Figure 19. SEM characterization of fouled membranes : base membrane after the first DCMD run: (a) base membrane challenged with PW; (b) base membrane challenged with EC pretreated PW; and, (c) base membrane challenged with synthetic PW, 5 mins polymerized allyl modified membrane after the first DCMD run : d) allyl modified membrane challenged with PW; (e) allyl modified membrane challenged with EC pretreated PW; and, (f) allyl modified membrane challenged with synthetic PW. 
Table 6. EDX analysis of fouled membranes.

\begin{tabular}{|c|c|c|c|c|c|c|}
\hline \multirow{2}{*}{$\begin{array}{c}\text { Element } \\
\text { (at. \%) }\end{array}$} & \multicolumn{3}{|c|}{ Base } & \multicolumn{3}{c|}{ Allyl } \\
\cline { 2 - 7 } & $\mathrm{PW}$ & $\begin{array}{c}\text { EC pretreated } \\
\text { PW }\end{array}$ & $\begin{array}{c}\text { Synthetic } \\
\text { PW }\end{array}$ & PW & $\begin{array}{c}\text { EC pretreated } \\
\text { PW }\end{array}$ & $\begin{array}{c}\text { Synthetic } \\
\text { PW }\end{array}$ \\
\hline $\mathrm{C}$ & 33.8 & 75.43 & 87.96 & 92 & 84.32 & 80.07 \\
\hline $\mathrm{N}$ & 33.8 & 4.53 & 0.91 & 0.25 & 0.16 & 0.16 \\
\hline $\mathrm{Cl}$ & 14.4 & 10.5 & 9.36 & 3.08 & 7.2 & 11.44 \\
\hline $\mathrm{Ca}$ & 5.49 & 4.41 & 5.25 & 1.21 & 2.42 & 4.95 \\
\hline $\mathrm{Na}$ & 4.77 & 6.37 & 6.51 & 0.33 & 2.21 & 3.27 \\
\hline $\mathrm{Au}$ & 0.08 & 0.04 & 0.03 & 0.06 & 0.03 & 0.02 \\
\hline
\end{tabular}

Allyl modified membrane showed presence of $\mathrm{N}$ for all PW, synthetic PW, and EC pretreated PW. This could be attributed to the $\mathrm{N}$ present in the imidazolium ring. The amount of $\mathrm{N}$ present on allyl membranes was either lower or similar to $\mathrm{N}$ present on the base membrane surface due to organic fouling. This showed evidence of higher resistance to organic fouling of the allyl modified membrane.

After DCMD runs with PW, the O peak was found to be much less compared to base membrane. This also confirmed that the PIL grafting on PP membrane significantly improved the antifouling characteristic of membrane toward organic foulants. The results suggested that initial fouling was due to adsorption of organic compounds followed by scale formation due to the deposition of inorganic salts present in the PW.

The allyl modified membrane better resisted adsorption of these organic compounds. However, $\mathrm{Na}$ and $\mathrm{Cl}$ peaks were observed in EDX spectra revealing the existence of electrostatic interaction of PIL chains and the ions present in the PW. The results for synthetic PW and EC 
pretreated PW suggested that the allyl modified membrane did not indicate better resistance to scale formation when compared to the base PP membrane.

The results suggested that modification of the PP membrane with poly ionic liquid chains did provide additional resistance to fouling compared to the base PP membrane. The allyl modified membrane gave the greatest resistance to organic fouling. It was adsorption of organic species in the hydraulic fracturing PW that appeared to lead to initial fouling. Thus, suppressing adsorption of organic compounds provided better fluxes, most likely generating a more stable membrane.

The grafted polyionic liquid did not appear to better suppress the importance of minimizing the thickness of the surface modification. Results from this research indicate that over-modification can result in early pore wetting due to rapid adsorption of species in the PW. Further, the membrane pores must remain hydrophobic to prevent transfer of water into the distillate. Modification by grafting polymer chains that contain fixed charged groups could be a promising way to develop more stable membranes for DCMD. The results suggest that pretreatment to reduce the TOC and TSS will be essential but by grafting polymers with fixed charges, membrane lifetime and the degree of pretreatment could be minimized. 


\section{Conclusion}

Microporous PP membranes have been modified by grafting polyHEMA, polyAA, polyvinylallyl imidazolium bromide and polyvinylhexyl imidazolium bromide and chains by UV initiated polymerization. When challenged with PW, the membrane grafted with polyvinylallyl imidazolium bromide gave the best performance. The presence of fixed charged groups on the grafted polymer chains appear to suppress fouling by organic species present in the PW. Surface characterization by measuring contact angle, SEM imaging, FTIR, and EDX analysis indicate that initial adsorption of organic species in the PW leads to flux decline. Subsequent scale formation by inorganic species in the PW can lead to pore wetting and passage of water from the feed to the distillate.

Since it is water vapor that passes through the membrane pores, it is essential that the membrane is hydrophobic. Since grafting hydrophilic polymers from the membrane surface results in a decrease in contact angle, it is essential the thickness of the grafted nanostructure is minimized. The results obtained here indicate that pretreatment of the PW feed stream is essential to reduce TOC and TSS. For the polyvinylallyl imidazolium bromide modified membrane, the stability of the membrane is enhanced. Further pretreatment requirements, i.e., reduction of TOC and TSS, may be less than the base PP membrane. Membrane surface modification provides a way to tune the membrane properties in order to minimize the likelihood of membrane failure by pore wetting. 


\section{References}

[1] A. Fakhru'l-Razi, A. Pendashteh, L.C. Abdullah, D.R.A. Biak, S.S. Madaeni, Z.Z. Abidin, Review of technologies for oil and gas produced water treatment, J. Hazard. Mater. 170 (2009) 530-551. doi:10.1016/j.jhazmat.2009.05.044.

[2] C. Clark, J. Veil, Produced Water Volumes and Management Practices in the United States, Argonne Natl. Lab. Rep. (2009) 64. doi:10.2172/1007397.

[3] G.T. Tellez, N. Nirmalakhandan, J.L. Gardea-Torresdey, Kinetic evaluation of a fieldscale activated sludge system for removing petroleum hydrocarbons from oilfieldproduced water, Environ. Prog. 24 (2005) 96-104. doi:10.1002/ep.10042.

[4] K.B. Gregory, R.D. Vidic, D.A. Dzombak, Water management challenges associated with the production of shale gas by hydraulic fracturing, Elements. 7 (2011) 181-186. doi:10.2113/gselements.7.3.181.

[5] A. Vengosh, R.B. Jackson, N. Warner, T.H. Darrah, A. Kondash, A Critical Review of the Risks to Water Resources from Shale Gas Development and Hydraulic Fracturing in the United States, Environ. Sci. Technol. 16 (2014) 6838. doi:10.1021/es405118y.

[6] U.S.E.I. Administration, Technically Recoverable Shale Oil and Shale Gas Resources : An Assessment of 137 Shale Formations in 41 Countries Outside the United States, U.S. Energy Inf. Adm. 2013 (2013) 76 pp. doi:www.eia.gov/analysis/studies/worldshalegas/.

[7] U.S. Energy Information Administration (EIA), (n.d.).https://www.eia.gov/tools/faqs/faq. php?id=907\&t=8.[Accessed: October 12, 2017]

[8] K. Sardari, P. Fyfe, D. Lincicome, S. Ranil Wickramasinghe, Combined electrocoagulation and membrane distillation for treating high salinity produced waters, J. Memb. Sci. 564 (2018) 82-96. doi:10.1016/j.memsci.2018.06.041.

[9] K. Sardari, P. Fyfe, D. Lincicome, S.R. Wickramasinghe, Aluminum electrocoagulation followed by forward osmosis for treating hydraulic fracturing produced waters, Desalination. 428 (2018) 172-181. doi:10.1016/j.desal.2017.11.030.

[10] Induced Earthquakes, (n.d.). https://earthquake.usgs.gov/research/induced/myths.php. [Accessed: October 12, 2017]

[11] M. Takht Ravanchi, T. Kaghazchi, A. Kargari, Application of membrane separation processes in petrochemical industry: a review, Desalination. 235 (2009) 199-244. doi:10.1 016/j.desal.2007.10.042.

[12] S. Munirasu, M.A. Haija, F. Banat, Use of membrane technology for oil field and refinery produced water treatment - A review, Process Saf. Environ. Prot. 100 (2016) 183-202. doi:10.1016/j.psep.2016.01.010. 
[13] A. Alkhudhiri, N. Darwish, N. Hilal, Membrane distillation : A comprehensive review, Distillation, 287 (2012) 2-18. doi:10.1016/j.desal.2011.08.027.

[14] C. Charcosset, R. Kieffer, D. Mangin, F. Puel, Coupling between membrane processes and crystallization operations, Ind. Eng. Chem. Res. 49 (2010) 5489-5495. doi:10.1021/ie901 $824 x$.

[15] E. Drioli, M. Romano, Progress and New Perspectives on Integrated Membrane Operations for Sustainable Industrial Growth, Ind. Eng. Chem. Res. 40 (2001) 1277-1300. doi:10.1021/ie0006209.

[16] A. Deshmukh, C. Boo, V. Karanikola, S. Lin, A.P. Straub, T. Tong, D.M. Warsinger, M. Elimelech, Membrane distillation at the water-energy nexus: Limits, opportunities, and challenges, Energy Environ. Sci. 11 (2018) 1177-1196. doi:10.1039/c8ee00291f.

[17] B. Van Der Bruggen, C. Vandecasteele, T. Van Gestel, W. Doyen, R. Leysen, A review of pressure-driven membrane processes in wastewater treatment and drinking water production, Environ. Prog. 22 (2003) 46-56. doi:10.1002/ep.670220116.

[18] A.L. Lim, R. Bai, Membrane fouling and cleaning in microfiltration of activated sludge wastewater, J. Memb. Sci. 216 (2003) 279-290. doi:10.1016/S0376-7388(03)00083-8.

[19] A. Alkhudhiri, N. Darwish, N. Hilal, Produced water treatment: Application of Air Gap Membrane Distillation, Desalination. 309 (2013) 46-51. doi:10.1016/j.desal.2012.09.017.

[20] K.W. Lawson, D.R. Lloyd, Membrane distillation. II. Direct contact MD, J. Memb. Sci. 120 (1996) 123-133. doi:10.1016/0376-7388(96)00141-X.

[21] W. Guo, H.H. Ngo, J. Li, A mini-review on membrane fouling, Bioresour. Technol. 122 (2012) 27-34. doi:10.1016/j.biortech.2012.04.089.

[22] S. Nejati, C. Boo, C.O. Osuji, M. Elimelech, Engineering flat sheet microporous PVDF films for membrane distillation, J. Memb. Sci. 492 (2015) 355-363.

doi:10.1016/j.memsci.2015.05.033.

[23] C. Boo, J. Lee, M. Elimelech, Omniphobic Polyvinylidene Fluoride (PVDF) Membrane for Desalination of Shale Gas Produced Water by Membrane Distillation, Environ. Sci. Technol. 50 (2016) 12275-12282. doi:10.1021/acs.est.6b03882.

[24] C. Boo, J. Lee, M. Elimelech, Engineering Surface Energy and Nanostructure of Microporous Films for Expanded Membrane Distillation Applications, Environ. Sci. Technol. 50 (2016) 8112-8119. doi:10.1021/acs.est.6b02316.

[25] J. Lee, C. Boo, W. Ryu, A.D. Taylor, M. Elimelech, Development of Omniphobic Desalination Membranes Using a Charged Electrospun Nanofiber Scaffold, (2016). doi:10.1021/acsami.6b02419. 
[26] A. Razmjou, E. Arifin, G. Dong, J. Mansouri, V. Chen, Superhydrophobic modification of TiO 2 nanocomposite PVDF membranes for applications in membrane distillation, J.

Memb. Sci. 415-416 (2012) 850-863. doi:10.1016/j.memsci.2012.06.004.

[27] E. Lee, B.J. Deka, J. Guo, Y.C. Woo, H.K. Shon, A.K. An, Engineering the Re-Entrant Hierarchy and Surface Energy of PDMS- PVDF Membrane for Membrane Distillation Using a Facile and Benign Microsphere Coating, Environmental Science \& Technology. 51 (2017) 10117-10126. doi:10.1021/acs.est.7b01108.

[28] A. Tuteja, W. Choi, M. Ma, J.M. Mabry, S.A. Mazzella, G.C. Rutledge, G.H. Mckinley, R.E. Cohen, Designing Superoleophobic Surfaces, Science, (2007) 1618-1623. doi: 10. 1126/science. 1148326.

[29] S. Lin, S. Nejati, C. Boo, Y. Hu, C.O. Osuji, M. Elimelech, Omniphobic Membrane for Robust Membrane Distillation, Environ. Sci. Technol. Lett. 1 (2014) 443-447. doi:10.10 21/ez500267p.

[30] H. Huang, K. Schwab, Pretreatment for Low Pressure Membranes in Water Treatment: A Review, Environmental Science \& Technology, 43 (2009) 3011-3019. doi:doi:10.1021/e s802473r.

[31] P.K. Holt, G.W. Barton, C.A. Mitchell, The future for electrocoagulation as a localised water treatment technology, Chemosphere. 59 (2005) 355-367.doi:10.1016/j.chemosphere .2004.10.023.

[32] P.K. Holt, G.W. Barton, M. Wark, C.A. Mitchell, A quantitative comparison between chemical dosing and electrocoagulation, Colloids Surfaces A Physicochem. Eng. Asp. 211 (2002) 233-248. doi:10.1016/S0927-7757(02)00285-6.

[33] M. Kobya, O.T. Can, M. Bayramoglu, Treatment of textile wastewaters by electrocoagulation using iron and aluminum electrodes, J. Hazard. Mater. 100 (2003) 163178. doi:10.1016/S0304-3894(03)00102-X.

[34] K. Farahbakhsh, C. Svrcek, R.K. Guest, D.W. Smith, A review of the impact of chemical pretreatment on low-pressure water treatment membranes, J. Environ. Eng. Sci. 3 (2004) 237-253. doi:10.1139/s03-078.

[35] D. Mills, New process for electrocoagulation, J. / Am. Water Work. Assoc. 92 (2000) 3443. doi:10.1002/j.1551-8833.2000.tb08957.x.

[36] D. Ghernaout, B. Ghernaout, A. Saiba, A. Boucherit, A. Kellil, Removal of humic acids by continuous electromagnetic treatment followed by electrocoagulation in batch using aluminium electrodes, Desalination. 239 (2009) 295-308. doi:10.1016/j.desal.2008.04. 001 .

[37] D. Ghernaout, A.I. Al-ghonamy, M. Wahib, Influence of operating parameters on 
electrocoagulation of C . I . disperse yellow 3, Journal of Electrochemical Science and Engineering. 4 (2014) 271-283. doi:10.5599/jese.

[38] Z. Wang, S. Lin, Membrane fouling and wetting in membrane distillation and their mitigation by novel membranes with special wettability, Water Res. 112 (2017) 38-47. doi:10.1016/j.watres.2017.01.022.

[39] S.K. Ethirajan, A. Sengupta, M. Jebur, M. Kamaz, X. Qian, R. Wickramasinghe, SingleStep Synthesis of Novel Polyionic Liquids Having Antibacterial Activity and Showing $\pi$ Electron Mediated Selectivity in Separation of Aromatics, ChemistrySelect. 3 (2018) 4959-4968. doi:10.1002/slct.201800101.

[40] L.C. Tomé, D. Mecerreyes, C.S.R. Freire, L.P.N. Rebelo, I.M. Marrucho, Pyrrolidiniumbased polymeric ionic liquid materials: New perspectives for $\mathrm{CO} 2$ separation membranes, J. Memb. Sci. 428 (2013) 260-266. doi:10.1016/j.memsci.2012.10.044.

[41] J. Zhang, J. Liu, Y. Zuo, R. Wang, Y. Xiong, Preparation of thermo-responsive poly(ionic liquid)s-based nanogels via one-step cross-linking copolymerization, Molecules. 20 (2015) 17378-17392. doi:10.3390/molecules200917378.

[42] J. Qin, J. Guo, Q. Xu, Z. Zheng, H. Mao, F. Yan, Synthesis of Pyrrolidinium-Type Poly(ionic liquid) Membranes for Antibacterial Applications, ACS Appl. Mater. Interfaces. 9 (2017) 10504-10511. doi:10.1021/acsami.7b00387.

[43] T. Welton, Room-Temperature Ionic Liquids. Solvents for Synthesis and Catalysis, Chem. Rev. 99 (1999) 2071-2084. doi:10.1021/cr980032t.

[44] W. Song, Z. Guo, L. Zhang, H. Zheng, Z. Zhao, Antibacterial activity of starch/ acrylamide/allyl triphenyl phosphonium bromide copolymers synthesized by gamma irradiation, Radiat. Phys. Chem. 91 (2013) 114-119. doi:10.1016/j.radphyschem. 2013.06.003.

[45] Y. Xue, Y. Pan, H. Xiao, Y. Zhao, Novel quaternary phosphonium-type cationic polyacrylamide and elucidation of dual-functional antibacterial/antiviral activity, RSC Adv. 4 (2014) 46887-46895. doi:10.1039/c4ra08634a.

[46] Z. Zheng, Q. Xu, J. Guo, J. Qin, H. Mao, B. Wang, F. Yan, Structure-Antibacterial Activity Relationships of Imidazolium-Type Ionic Liquid Monomers, Poly(ionic liquids) and Poly(ionic liquid) Membranes: Effect of Alkyl Chain Length and Cations, ACS Appl. Mater. Interfaces. 8 (2016) 12684-12692. doi:10.1021/acsami.6b03391.

[47] Z. Wang, D. Hou, S. Lin, Composite Membrane with Underwater-Oleophobic Surface for Anti-Oil-Fouling Membrane Distillation, Environ. Sci. Technol. 50 (2016) 3866-3874. doi:10.1021/acs.est.5b05976.

[48] E. The United States Environmental Protection Agency, Title : Residue, Filterable 
(Gravimetric, Dried at $180^{\circ} \mathrm{C}$ ) METHOD \#: 160.1, Methods. 81 (1971) 5-7.

[49] E. The United States Environmental Protection Agency, Residue, Non-Filterable (Gravimetri, Dried at 103-105C) METHOD \#: 160.2, (1971) 3.

[50] M. Jebur, A. Sengupta, Y.H. Chiao, M. Kamaz, X. Qian, R. Wickramasinghe, Pi electron cloud mediated separation of aromatics using supported ionic liquid (SIL) membrane having antibacterial activity, J. Memb. Sci. 556 (2018) 1-11. doi:10.1016/j.memsci.2018. 03.064 .

[51] A. Rahimpour, S.S. Madaeni, S. Zereshki, Y. Mansourpanah, Preparation and characterization of modified nano-porous PVDF membrane with high antifouling property using UV photo-grafting, Appl. Surf. Sci. 255 (2009) 7455-7461. doi:10.1016/j.apsusc.20 09.04.021.

[52] N. Shahkaramipour, T.N. Tran, S. Ramanan, H. Lin, Membranes with surface-enhanced antifouling properties for water purification, Membranes (Basel). 7 (2017) 1-18. doi:10. 3390/membranes 7010013 .

[53] H. Dong, H. Du, X. Qian, Theoretical prediction of $\mathrm{pKa}$ values for methacrylic acid oligomers using combined quantum mechanical and continuum solvation methods., J. Phys. Chem. A. 112 (2008) 12687-94. doi:10.1021/jp807315p.

[54] R.J. Vonk, S. Wouters, A. Barcaru, G. Vivó-Truyols, S. Eeltink, L.J. de Koning, P.J. Schoenmakers, Post-polymerization photografting on methacrylate-based monoliths for separation of intact proteins and protein digests with comprehensive two-dimensional liquid chromatography hyphenated with high-resolution mass spectrometry, Anal. Bioanal. Chem. 407 (2015) 3817-3829. doi:10.1007/s00216-015-8615-4.

[55] A. Shakeri, A. Ghasemian, Water absorption and thickness swelling behavior of polypropylene reinforced with hybrid recycled newspaper and glass fiber, Appl. Compos. Mater. 17 (2010) 183-193. doi:10.1007/s10443-009-9111-9.

[56] A.P. Metzger, J.D. Matlack, Comparative swelling behavior of various thermoplastic polymers, Polym. Eng. Sci. 8 (1968) 110-115.

[57] K.H. Hong, N. Liu, G. Sun, UV-induced graft polymerization of acrylamide on cellulose by using immobilized benzophenone as a photo-initiator, Eur. Polym. J. 45 (2009) $2443-$ 2449. doi:10.1016/j.eurpolymj.2009.04.026.

[58] K. Wang, Y. Lu, P. Chen, J. Shi, H. Wang, Q. Yu, Novel one-component polymeric benzophenone photoinitiator containing poly (ethylene glycol) as hydrogen donor, Mater. Chem. Phys. 143 (2014) 1391-1395. doi:10.1016/j.matchemphys.2013.11.051.

[59] M. Jordi, Case Study FTIR for Identification of Contamination, Jordi Labs LLC. (2017), https://jordilabs.com/knb/case-studies/ftir-identification-contamination/ [Accessed: 
September 14, 2018]

[60] B.M. Carter, A. Sengupta, X. Qian, M. Ulbricht, S.R. Wickramasinghe, Controlling external versus internal pore modification of ultrafiltration membranes using surfaceinitiated AGET-ATRP, J. Memb. Sci. 554 (2018) 109-116. doi:10.1016/j.memsci.2018. 02.066 .

[61] G. Song, A. Sengupta, X. Qian, S.R. Wickramasinghe, Investigation on suppression of fouling by magnetically responsive nanofiltration membranes, Sep. Purif. Technol. 205 (2018) 94-104. doi:10.1016/j.seppur.2018.05.022.

[62] M. Malmali, P. Fyfe, D. Lincicome, K. Sardari, S.R. Wickramasinghe, Selecting membranes for treating hydraulic fracturing produced waters by membrane distillation, Sep. Sci. Technol. 52 (2017) 266-275. doi:10.1080/01496395.2016.1244550.

[63] P. K. Morse, E. I. Corwin, Electronic Supplementary Material (ESI) for Soft Matter, The Royal Society of Chemistry, 12 (2011) 5-7. doi:10.1039/C5SM02575C 


\section{Appendix A: Description of Research for Popular Publication}

Freshwater is essential to everyday societal activities. Discharging wastewater containing organic and inorganic contaminants can be harmful to ecosystems and fresh water systems. As the oil and natural gas production is increasing to meet the demands of modern society, generation of large volumes of waste streams are also increasing. These oil and gas waste streams or produced water (PW) contains an extensive amount of organic and inorganic components. Discharging these PW to the environment can be very harmful to surface water as well as underground water and soil. Since these PWs are generated in large volumes, there is a growing need for efforts to find efficient and environmentally friendly methods to treat and remove pollutants in these PWs. This can also provide a supplemental solution for limited freshwater resource.

There is a rapid growth of natural gas production using horizontal drilling and highvolume hydraulic fracturing in the United States. According to the U.S. Energy Information Administration, 15.8 trillion cubic feet of natural gas was produced the U.S. in 2016. Hydraulic fracturing produced water is considered as the largest waste produced in the oil and gas industry due to large quantities of PW generated from the hydraulic fracturing process. Management and disposal of this produced water have become one of the biggest challenges in the oil and gas development industry. Deep-well injection is the primary method of disposal and management of these high salinity PWs. This process can cost up to 10 to 15 USD per barrel of PW. In addition to the high operation costs, U.S geological survey (USGS) has recently discovered that the deep-well injection wastewater disposal is the principal cause of the recent increase in earthquakes in the central U.S. Therefore, there is an urgent need for novel processes to eliminate or minimize the deep-well injection. 
Membrane technology plays a vital role in wastewater treatment applications. A membrane can be utilized as a barrier that limits transport of undesired species and enables transport of targeted desired species. Development of an efficient membrane separation process to treat produced water can minimize the deep well injection. However, contaminants present in the produced waters can hinder performance of membrane separation process eventually leading to higher operation costs. These research results have the potential to improve membrane separation technology to be used in treating these produced waters and minimize the volume of disposal. Improving on these research results can lead to an efficient and environmentally friendly method to treat and remove pollutants in these PWs. 


\section{Appendix B: Executive Summary of Newly Created Intellectual Property}

The following list of new intellectual property items were created in the course of this research project and should be considered from both a patent and commercialization perspective.

1. A method for grafting membrane surfaces to provide new physical properties to suppress membrane fouling.

2. A process to combine electrocoagulation pretreatment method with grafted membranes to suppress membrane fouling. 


\section{Appendix C: Potential Patent and Commercialization Aspects of listed Intellectual \\ Property Items}

C.1 Patentability of Intellectual Property (Could Each Item be Patented)

The two items listed were considered first from the perspective of whether the item could be patented or not.

1. The grafted physical properties of membrane surfaces cannot be patented. There are other methods that can provide same physical properties to membrane surface and they have been used to membrane surface modification. [1] This research needs future work to distinguish from existing grafting processes.

2. Electrocoagulation pretreatment process is well known process. This process is incorporated in this research work as a pretreatment to enhance the membrane fouling suppression. Prior research works have widely used electrocoagulation as a pretreatment process combined with different techniques. [1]

C.2 Commercialization Prospects (Should Each Item Be Patented)

The two items listed in Appendix C.1 cannot be patented, hence they are not commercialization prospects.

\section{C.3 Possible Prior Disclosure of IP}

The following items were discussed in a public forum or have published information that could impact the patentability of the listed IP.

1. N/A

2. The process of combining electrocoagulation pretreatment method with grafted membranes to suppress membrane fouling was conducted by K. Sardari and the group at the 
University of Arkansas Membrane Research Center. Research group has published their

findings.

K. Sardari, P. Fyfe, D. Lincicome, S. Ranil Wickramasinghe, Combined electrocoagulation and membrane distillation for treating high salinity produced waters, J. Memb. Sci. 564 (2018) 8296. doi:10.1016/j.memsci.2018.06.041.

\section{Reference}

[1] A. Deshmukh, C. Boo, V. Karanikola, S. Lin, A.P. Straub, T. Tong, D.M. Warsinger, M. Elimelech, Membrane distillation at the water-energy nexus: Limits, opportunities, and challenges, Energy Environ. Sci. 11 (2018) 1177-1196. doi:10.1039/c8ee00291f. 


\section{Appendix D: Broader Impact of Research}

D.1 Applicability of Research Methods to Other Problems

Membrane distillation is an emerging technology for treating polluted water including hydraulic fracturing flowback and produced waters. Suppression of membrane fouling by inorganic and polar and non-polar organic compounds is a challenge in these treating procedures. Fouling is initially due to adsorption of organic compounds followed by scale formation. When challenged with polluted water, modified membranes provided the greater resistance to fouling. This method can be used in any membrane distillation process to address membrane fouling.

\section{D.2 Impact of Research Results on U.S. and Global Society}

Freshwater is essential to everyday societal activities. Discharging wastewater containing organic and inorganic contaminants can be harmful to ecosystems and fresh water systems. As the oil and natural gas production is increasing to meet the demands of modern society, generation of large volumes of waste streams are also increasing. These oil and gas waste streams or produced water (PW) contains an extensive amount of organic and inorganic components. Discharging these PW to the environment can be very harmful to surface water as well as underground water and soil. Since these PWs are generated in large volumes, there is a growing need for efforts to find efficient and environmentally friendly methods to treat and remove pollutants in these PWs. This can also provide a supplemental solution for limited freshwater resource.

These research results have the potential to improve membrane separation technology to be used in treating these produced waters and minimize the volume of disposal. Improving on these research results can lead to an efficient and environmentally friendly method to treat and remove pollutants in these PWs. 
D.3 Impact of Research Results on the Environment

Deep-well injection is the primary method of disposal and management of these high salinity produced waters. U.S geological survey (USGS) has recently discovered that the deepwell injection wastewater disposal is the principal cause of the recent increase in earthquakes in the central U.S. Therefore, there is an urgent need for novel processes to eliminate or minimize the deep-well injection. These research results have the potential to improve membrane separation technology to be used in treating these produced waters and minimize the volume of disposal which eventually can lead to limiting deep well injection. 


\section{Appendix E: Microsoft Project for MS MicroEP Degree Plan}

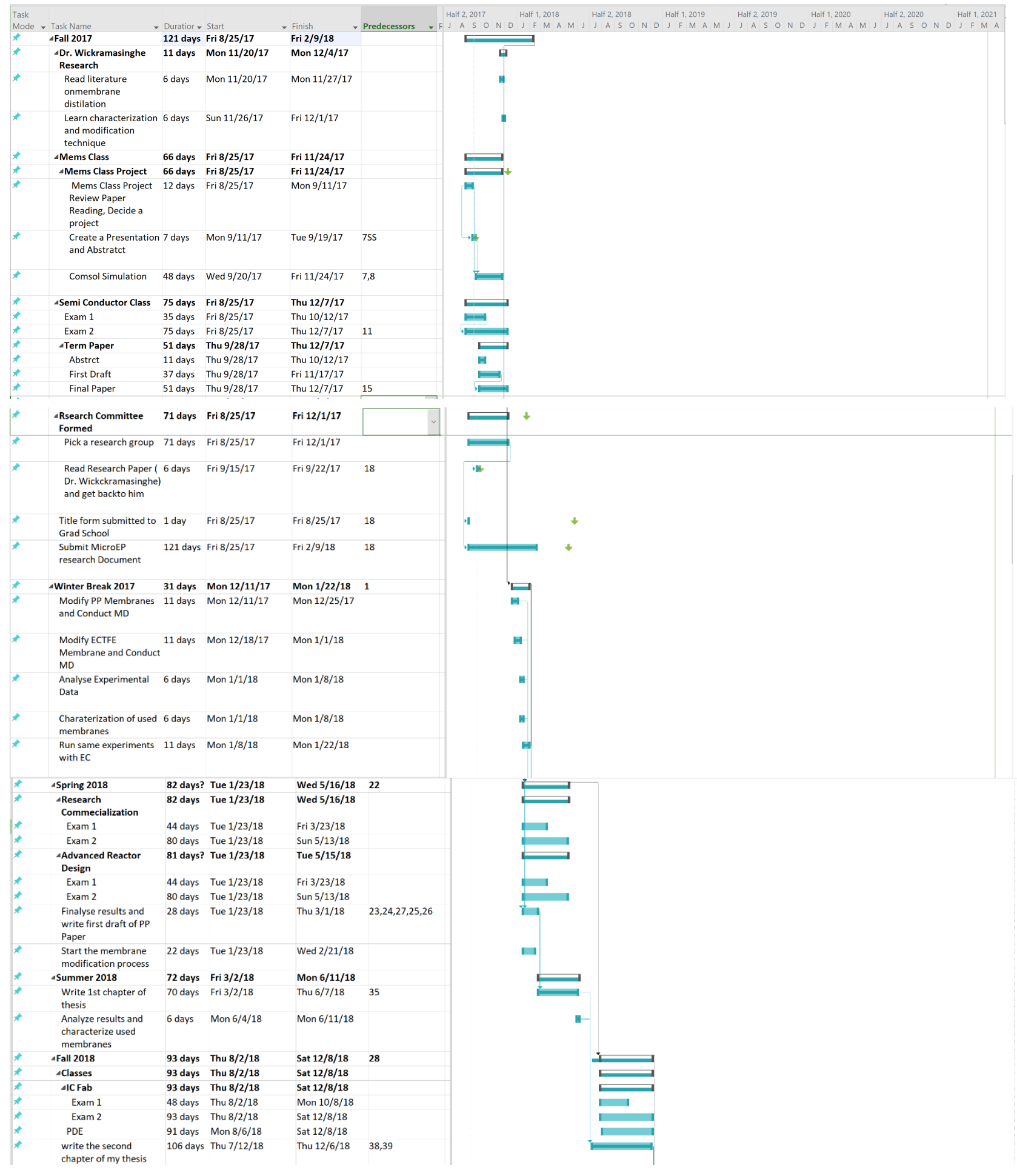




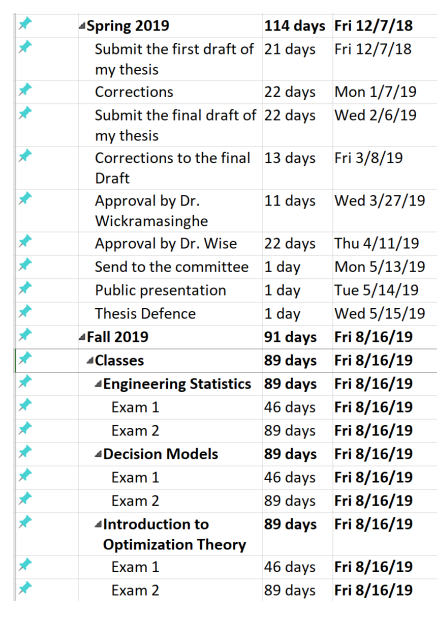

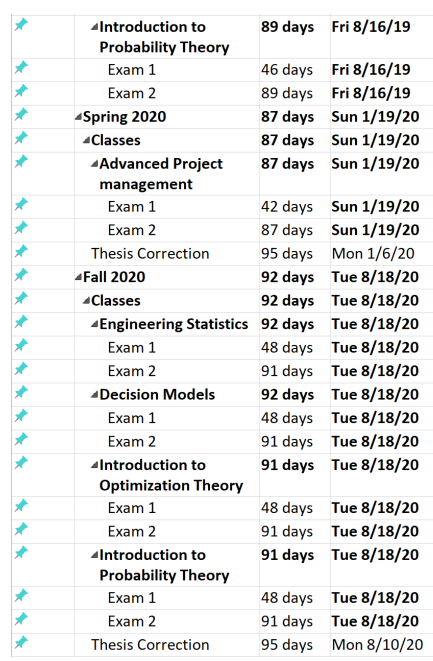

\begin{tabular}{|c|c|c|c|c|c|}
\hline * & $\triangle$ Spring 2021 & 107 days & Mon $12 / 21 / 20$ & Tue $5 / 18 / 21$ & 77 \\
\hline t & $\triangle$ Classes & 92 days & Sun $1 / 10 / 21$ & Sun $5 / 16 / 21$ & \\
\hline * & $\begin{array}{l}\triangle \text { Strategic } \\
\text { Management }\end{array}$ & 92 days & Sun $1 / 10 / 21$ & Sun $5 / 16 / 21$ & \\
\hline * & Exam 1 & 48 days & Sun $1 / 10 / 21$ & Tue $3 / 16 / 21$ & \\
\hline * & Exam 2 & 92 days & Sun $1 / 10 / 21$ & Sun $5 / 16 / 21$ & \\
\hline t & Submit Corrected Thesis & 35 days & Sun $1 / 10 / 21$ & Thu $2 / 25 / 21$ & 91 \\
\hline t & Apply for Graduation & 1 day & Mon 3/1/21 & Mon $3 / 1 / 21$ & 97 \\
\hline * & Graduation & 1 day & Fri $5 / 14 / 21$ & Fri $5 / 14 / 21$ & 98 \\
\hline
\end{tabular}

Wed 12/23/20 71

Wed 12/23/20

Wed 12/23/20

Thu 10/22/20

Tue 12/22/20

Wed $12 / 23 / 20$
Thu $10 / 22 / 20$

Thu 10/22/20

Tue 12/22/20

Thu 10/22/20

Tue 12/22/20

Tue 12/22/20

Thu 10/22/20
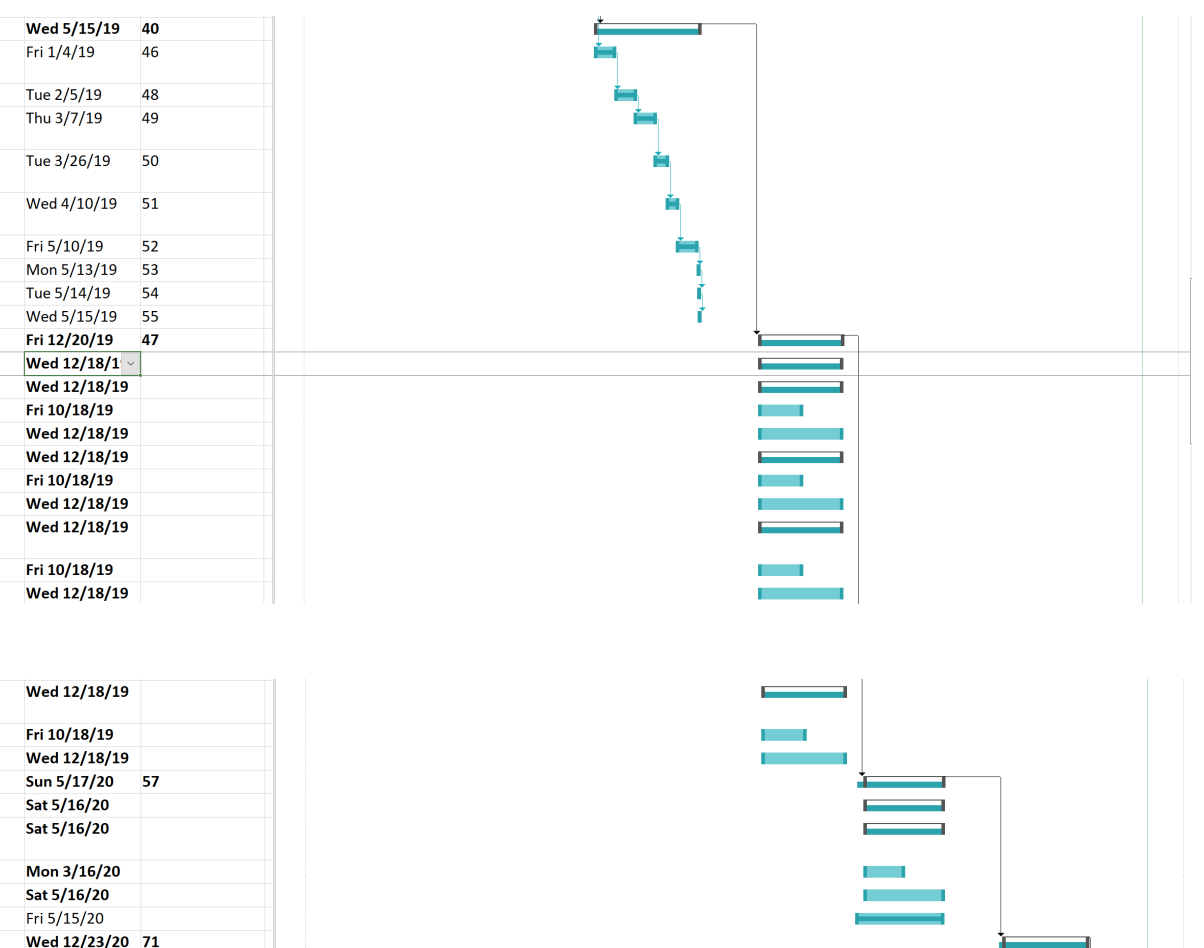

Tue 12/22/20
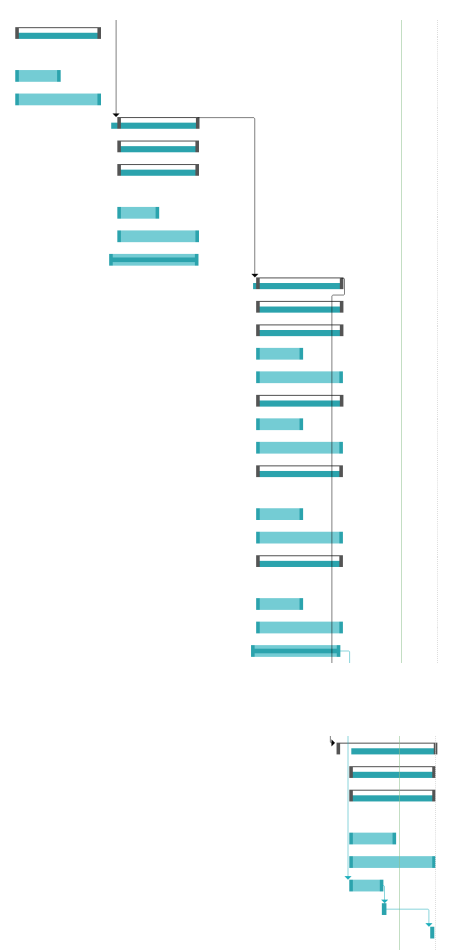


\section{Appendix F: Identification of All Software Used in Research and Thesis Generation}

1- Computer \#1: DELL

Model Number: Dell Optiplex 390

Serial Number: 7215609313

Location: CSRC

Owner: Dr. Ranil Wickramsinghe

Software \#1:

Name: Microsoft Office 2007

Purchased by: University of Arkansas Chemical Engineering Department.

Software \#2:

Name: Adobe Acrobat Professional 10.0

Purchased by: University of Arkansas Site License 68

Software \#3:

Name: Microsoft project

Purchased by: Microelectronics-Photonics graduate program, University of Arkansas 


\section{Appendix G: All Publications Published, Submitted, and Planned}

\section{Submitted}

Tharaka Gamage, Arijit Sengupta, S. Ranil Wickramasinghe, Surface modified polypropylene membranes for treating hydraulic fracturing produced waters by membrane distillation, Ralph $\mathrm{E}$. Martin Department of Chemical Engineering, University of Arkansas, Fayetteville, AR, USA. (Submitted to Journal of Separation Science and Technology) 


\section{Appendix H: Copyright Information}

Copyright Information for Taylor \& Francis

Tharaka Gamage, Arijit Sengupta \& S. Ranil Wickramasinghe "Surface modified polypropylene membranes for treating hydraulic fracturing produced waters by membrane distillation", Separation Science and Technology, vol. 54:17, p. 2921-2932, 2019 DOI:

10.1080/01496395.2019.1611854

Surface modified polypropylene membranes for treating hydraulic fracturing produced watersby membrane distillation

Author: Tharaka Gamage,, Arijit Sengupta, et al

Publication: Separation Science \& Technology

Publisher: Taylor \& Francis

Date: Nov 22, 2019

Rights managed by Taylor \& Francis

Thesis/Dissertation Reuse Request

Taylor \& Francis is pleased to offer reuses of its content for a thesis or dissertation free of charge contingent on resubmission of permission request if work is published. 